\title{
Evaluation of neurobehavioral abnormalities and immunotoxicity in response to oral imidacloprid exposure in domestic chickens (Gallus gallus domesticus)
}

Dana Franzen-Klein, Mark Jankowski, Charlotte L. Roy, Hoa Nguyen-Phuc, Da Chen, Lorin Neuman-Lee, Patrick Redig \& Julia Ponder

To cite this article: Dana Franzen-Klein, Mark Jankowski, Charlotte L. Roy, Hoa Nguyen-Phuc, Da Chen, Lorin Neuman-Lee, Patrick Redig \& Julia Ponder (2020): Evaluation of neurobehavioral abnormalities and immunotoxicity in response to oral imidacloprid exposure in domestic chickens (Gallus gallus domesticus), Journal of Toxicology and Environmental Health, Part A, DOI: 10.1080/15287394.2020.1723154

To link to this article: https://doi.org/10.1080/15287394.2020.1723154

View supplementary material $₫$

Published online: 05 Feb 2020.

Submit your article to this journal $\widetilde{ }$

Q View related articles 주

View Crossmark data $\asymp$ 


\title{
Evaluation of neurobehavioral abnormalities and immunotoxicity in response to oral imidacloprid exposure in domestic chickens (Gallus gallus domesticus)
}

\author{
Dana Franzen-Klein (10), Mark Jankowski ${ }^{\mathrm{a}, \mathrm{b}}$, Charlotte L. Roy ${ }^{\mathrm{c}}$, Hoa Nguyen-Phuc ${ }^{\mathrm{a}}$, Da Chen ${ }^{\mathrm{d}}$, Lorin Neuman-Lee ${ }^{\mathrm{e}}$, \\ Patrick Rediga, and Julia Ponder \\ aVeterinary Population Medicine Department, College of Veterinary Medicine, University of Minnesota, St. Paul, MN, USA; ${ }^{b}$ Laboratory \\ Services and Applied Science Division, United States Environmental Protection Agency, Seattle, WA, USA; 'Forest Wildlife Populations and \\ Research Group, Minnesota Department of Natural Resources, Grand Rapids, MN, USA; 'Cooperative Wildlife Research Laboratory and \\ Department of Zoology, Southern Illinois University, Carbondale, IL, USA; 'Department of Biological Sciences, Arkansas State University, \\ Jonesboro, AR, USA
}

\begin{abstract}
Domestic chickens (Gallus gallus domesticus) were exposed to imidacloprid by gavage once daily for 7 consecutive days at $0,0.03,0.34,3.42,10.25$, and $15.5 \mathrm{mg} / \mathrm{kg} / \mathrm{day}$ ( $\mathrm{n}=20$ per group; 5 6-week-old males, 5 6-week-old females, 5 9-week-old males, and 5 9-week-old females). The severity and duration of neurobehavioral abnormalities were recorded. Components of the innate and adaptive immune system were assessed with 7 standard functional assays. Temporary neurobehavioral abnormalities were observed in a dose-dependent manner, including muscle tremors, ataxia, and depressed mentation. Based upon mean clinical severity scores, the no observed adverse effect level (NOAEL) was $3.42 \mathrm{mg} / \mathrm{kg} / \mathrm{day}$, and the lowest observed adverse effect level (LOAEL) was $10.25 \mathrm{mg} / \mathrm{kg} /$ day. The effective dose value for the presence of any neurobehavioral abnormalities in $50 \%$ of the test group $\left(E D_{50}\right.$ ) was $4.62 \pm 0.98 \mathrm{mg} / \mathrm{kg} /$ day. The $E D_{50}$ for an adjusted score that included both severity and duration of neurobehavioral abnormalities was $11.24 \pm 9.33 \mathrm{mg} / \mathrm{kg} / \mathrm{day}$. These $\mathrm{ED}_{50}$ values are equivalent to a $1 \mathrm{~kg}$ bird ingesting 29 or 70 imidacloprid treated soybean seeds respectively. Immunotoxicity was not documented, possible causes include the assays were insensitive, relevant immune functions were not examined, or imidacloprid is not immunotoxic at this dosing schedule in this species. Neurobehavioral abnormalities were a more sensitive indicator of the sublethal effects of imidacloprid than immunotoxicity.
\end{abstract}

\section{KEYWORDS}

Avian toxicity; behavioral toxicology; neurotoxicity; neonicotinoids; risk assessment

\section{Introduction}

Neonicotinoids are a group of insecticides which currently include acetamiprid, clothianidin, dinotefuran, imidacloprid, nitenpyram, thiacloprid, and thiamethoxam. Neonicotinoids are currently the most widely used class of insecticides on the global market due to several factors including their low vertebrate toxicity compared to other insecticides such as organophosphates, systemic chemical distribution within the plant, and efficacy against a wide range of insects at low concentrations (Jeschke et al. 2011; Simon-Delso et al. 2015). Neonicotinoids are versatile with multiple application methods, including foliar sprays, granular soil applications, mixing with irrigation water, and external seed coating (Goulson 2013; Jeschke et al. 2011; Simon-Delso et al. 2015; Stephenson and Solomo 2017). Prophylactic seed coating is the most extensively used application method, with seed coating on corn constituting the largest single use of these compounds in North America (Jeschke et al. 2011; Simon-Delso et al. 2015). When measured by geographic area, neonicotinoids are the most widely utilized class of agricultural insecticide in United States history, totaling 97.4 million hectares (240.7 million acres) in 2013 (Simon-Delso et al. 2015).

The widespread use of neonicotinoids and associated environmental contamination has raised concerns regarding impacts on local ecosystems and nontarget species (Goulson 2013; Pisa et al. 2017; van der Sluijs et al. 2015). Birds seem to be particularly susceptible to adverse effects from neonicotinoids, with imidacloprid being the most toxic to avian species (Mineau and Palmer 2013). Birds may be exposed to neonicotinoids via multiple routes, including ingestion

CONTACT Dana Franzen-Klein franz337@umn.edu $\mathrm{E}$ The Raptor Center, University of Minnesota College of Veterinary Medicine, 1920 Fitch Ave, St. Paul, MN 55108, USA

(4) Supplementary data for this article can be accessed publisher's website. 
of treated seeds as well as dermal contact or inhalation of foliar sprays (Gibbons, Morrissey, and Mineau 2015; Goulson 2013; Mineau and Palmer 2013).

Reported sub-lethal effects resulting from neonicotinoid exposure in birds include neurobehavioral abnormalities in house sparrows (Passer domesticus), canaries (Serinus canaries), rock doves (Columba livia), northern bobwhite quail (Colinus virginianus), Japanese quail (Coturnix japonica), and mallards (Anas platyrhynchos), immunotoxicity in red-legged partridges (Alectoris rufa), impaired growth and development in northern bobwhite quail, and reduced reproductive success in Japanese quail, mallards, redlegged partridges, and northern bobwhite quail (Gibbons, Morrissey, and Mineau 2015; Mineau and Palmer 2013). Neurobehavioral abnormalities include hypo-reactivity, ataxia, immobility, muscle tremors, respiratory distress, and impaired migration (Eng, Stutchbury, and Morrissey 2017, 2019; Gibbons, Morrissey, and Mineau 2015). Impaired fatty acid metabolism induced by neonicotinoids may account for observations of impaired migration (Eng, Stutchbury, and Morrissey 2019). Immunotoxicity is a noteworthy sublethal effect because it has been linked with reduced survival probability and fitness in birds as reviewed in Fairbrother, Smits, and Grasman (2004). Nicotinic-acetylcholine receptors are the target for neonicotinoid pesticides, and are present in several components of the immune system (Jeschke et al. 2011; Kawashima and Fujii 2000), which may play a role in the observed immune suppression in bees, rodents and birds (Badgujar et al. 2013; Brandt et al. 2016; Kammon et al. 2012).

The objective of the present study was to facilitate ecological risk assessments by quantifying neurobehavioral abnormalities and immunotoxicity after oral imidacloprid exposure in birds in a dose-dependent manner. Domestic white leghorn chickens (Gallus gallus domesticus) were employed as a model for wild seed-eating gallinaceous birds. Imidacloprid doses were intended to represent realistic field exposures for a medium-sized granivorous bird.

\section{Materials and methods}

\section{Study design}

Domestic chickens were obtained from a commercial poultry farm at 5 and 8 weeks (wk) of age in 6 sequential groups (batches; 20-28 birds per batch) over a 17 wk period. All chickens were raised in the same manner prior to acquisition. Birds received coarse spray vaccinations at the poultry farm as follows: Newcastle disease and infectious bronchitis at 2 wk of age, Escherichia coli and infectious bronchitis at $4 \mathrm{wk}$ of age, and Newcastle disease, Salmonella typhimurium, and infectious bronchitis at $7 \mathrm{wk}$ of age.

At the research facility, chickens were identified with a numbered leg band and housed in groups of 10 to 15 separated by sex. All birds were given 7 to 8 days (d) to acclimate prior to the study. Housing consisted of 2-2.3 $\mathrm{m}^{2}$ stainless-steel pens with a cushioned, raised-floor (Suburban Surgical Co., Inc.). The temperature range was $21-24^{\circ} \mathrm{C}$. The room was ventilated through a MERV 8 pleated filter with an average of 11-12.6 air changes per h. The room lights were 40-watt fluorescent bulbs and set for $8 \mathrm{~h} \mathrm{light/d}$ for all birds. The first two batches of birds were housed in a room without windows. The last 4 batches of birds were housed in a room with windows that allowed access to natural light, which was up to $15 \mathrm{~h} / \mathrm{d}$. Birds were housed in two separate rooms due to requirements for other studies being conducted in the building. All individual birds were housed in the same environment for the duration of the study, and access to natural light was the only factor that changed between rooms. Birds were provided with enrichment items on a daily basis such as dust bathes. Birds had ad libitum access to water and food (game bird starter, Famo feeds ${ }^{\oplus}$, Freeport, MN). All birds were clinically healthy at the start of the study with no indications of underlying disease based on a physical exam and complete blood cell count (CBC).

Birds were randomly assigned to 6 treatment groups ( $\mathrm{n}=20$ per group) composed of 56 -wk-old males, 5 6-wk-old females, 5 9-wk-old males, and 5 9-wk-old females. Confirmed imidacloprid doses in the treatment groups were $0 \mathrm{mg} / \mathrm{kg} / \mathrm{d}, 0.03 \mathrm{mg} / \mathrm{kg} / \mathrm{d}$ ( $0.03 \%$ of the reported $\mathrm{LD}_{50}$ in domestic chickens (104.1 mg/kg) (Kammon et al. 2010)), $0.34 \mathrm{mg} / \mathrm{kg} / \mathrm{d}$ (0.3\% LD $\left.\mathrm{L}_{50}\right), 3.42 \mathrm{mg} / \mathrm{kg} / \mathrm{d}\left(3.3 \% \mathrm{LD}_{50}\right), 10.25 \mathrm{mg} / \mathrm{kg} /$ $\mathrm{d}\left(9.8 \% \mathrm{LD}_{50}\right)$, and $15.5 \mathrm{mg} / \mathrm{kg} / \mathrm{d}\left(14.9 \% \mathrm{LD}_{50}\right)$. Birds from batch 1 and $2(\mathrm{n}=51$ total) were randomly assigned among treatment groups $(0 \mathrm{mg} / \mathrm{kg} / \mathrm{d}$ $\mathrm{n}=11 ; 0.03 \mathrm{mg} / \mathrm{kg} / \mathrm{d} \mathrm{n}=11 ; 0.34 \mathrm{mg} / \mathrm{kg} / \mathrm{d} \mathrm{n}=9$; $3.42 \mathrm{mg} / \mathrm{kg} / \mathrm{d} \mathrm{n}=10 ; 10.25 \mathrm{mg} / \mathrm{kg} / \mathrm{d} \mathrm{n}=10 ; 15.50 \mathrm{mg} /$ 
$\mathrm{kg} / \mathrm{d} \mathrm{n}=10$ ), as were birds from the remaining 4 batches ( $\mathrm{n}=69$ total; $0 \mathrm{mg} / \mathrm{kg} / \mathrm{d} \mathrm{n}=9 ; 0.03 \mathrm{mg} / \mathrm{kg} / \mathrm{d}$ $\mathrm{n}=9 ; 0.34 \mathrm{mg} / \mathrm{kg} / \mathrm{d} \mathrm{n}=11 ; 3.42 \mathrm{mg} / \mathrm{kg} / \mathrm{d} \mathrm{n}=10 ;$ $10.25 \mathrm{mg} / \mathrm{kg} / \mathrm{d} \mathrm{n}=10 ; 15.5 \mathrm{mg} / \mathrm{kg} / \mathrm{d} \mathrm{n}=20$ ).

In all treatment groups, birds were dosed by gavage once daily for 7 consecutive days (day $0-6)$ at approximately 24-hour (h) intervals ( \pm 2 h). Neurobehavioral signs were monitored daily. Blood was collected for a CBC and microbiocidal assay immediately prior to oral exposure on days $0,3,7,14$ and 21 . The phytohemagglutinin-A (PHA) response test was performed on days 7 and 8. Birds were exposed to Mycobacterium tuberculosis antigen on day 1 for delayed type hypersensitivity (DTH) test, and a tuberculin skin test was performed on days 14 and 15. Birds were exposed to sheep red blood cells (SRBCs) on day 1 , and blood was collected for agglutination and hemolysis titers on day 7. Birds were humanely euthanized for a complete gross necropsy and tissue collection on day 21 . The research protocol was approved by the University of Minnesota Institutional Animal Care and Use Committee (protocol \# 1610-34271A).

\section{Oral exposure}

A chemical standard of imidacloprid powder (Cat \# N-1226-100 mg, 99.4\% purity, ChemService Inc.) was dissolved in a corn oil and $10 \%$ ethanol vehicle. The aqueous solubility of imidacloprid is approximately $0.061 \mathrm{mg} / \mathrm{ml}$, therefore ethanol and corn oil were used as chemical vehicles in order to create higher concentration suspensions. Five concentrations of imidacloprid suspension were used $(0.02,0.15$, $1.5,5$ or $7.5 \mathrm{mg} / \mathrm{ml}$ ) so each bird received approximately the same volume of vehicle $(2 \mathrm{ml} / \mathrm{kg})$. The highest concentration suspension was prepared by dissolving neat material in ethanol, then mixing thoroughly with corn oil using sonication. The lower concentration suspensions were prepared by diluting the highest concentration with corn oil. The vehicle control group (0 $\mathrm{mg} / \mathrm{kg} / \mathrm{d})$ was exposed to an equivalent volume of vehicle solvent. The imidacloprid suspensions and vehicle solvent were stored at $2-3^{\circ}$ $\mathrm{C}$, protected from light to prevent photolysis and mixed thoroughly prior to each use.
The assigned imidacloprid exposure was mixed with a grain-based feeding formula (Lafeber's Nutristart baby bird formula) to mimic ingestion of treated seed at a total volume of $1.5 \mathrm{ml} / 100 \mathrm{~g}$ body weight. The primary ingredients of the feeding formula are rice flour, hydrolyzed soy protein, corn flour and oat flour; the dry power is mixed with warm water to make a slurry for gavage feeding.

Birds were weighed to the nearest gram (g) immediately prior to each exposure and the appropriate suspension volume was calculated from the daily weight. The size of the crop was scored as follows by 2 trained researchers as a proxy for how full the gastrointestinal tract was immediately prior to gavage: 0 empty, 1 mildly full, 2 moderately full, 3 very full. Birds were manually restrained, a lubricated feeding tube was passed into the ventriculus, the imidacloprid suspension and feeding formula were administered, then the tube was flushed with water to ensure the entire volume was administered. No regurgitation was noted during the minimum 30-minute ( $\mathrm{min}$ ) observation period after gavage.

Neonicotinoid concentrations in the suspension, gavage feeding formula and chicken feed were measured using high performance liquid chromatography (HPLC) tandem mass spectrometry (MS) on an Agilent 1260 HPLC system interfaced with a 3200 QTrap triple quadrupole/linear ion trap MS (AB Sciex; Toronto, Canada) and equipped with a ZORBAX Extended-C18 column $(100 \times 2.1 \mathrm{~mm}$, $3.5 \mu \mathrm{m}, 80 \AA$, Agilent Technologies). The MS was equipped with a TurboIonSpray ${ }^{\oplus}$ electrospray ionization probe operated in the multiple reaction monitoring mode. The mobile phase consisted of methanol (A) and water (B), both spiked with $0.1 \%$ formic acid (v/v). The mobile phase flow rate was $200 \mu \mathrm{l} / \mathrm{min}$ and the following gradient was employed: $10 \% \mathrm{~B}$ ramped to $70 \% \mathrm{~B}$ in $11 \mathrm{~min}$ (linear) and then ramped to $80 \%$ $\mathrm{B}$ in 6 min (linear), followed by a linear increase to $90 \% \mathrm{~B}$ in $2 \mathrm{~min}$ (held for $1 \mathrm{~min}$ ) and then a change to $10 \% \mathrm{~B}$ in $1 \mathrm{~min}$ (held for $8 \mathrm{~min}$ ).

\section{Neurobehavioral abnormalities}

Neurobehavioral abnormalities were scored daily during the acclimation period and on every day of the study by 1 clinical avian veterinarian and 1 trained avian researcher based on set criteria derived from the modified Glasgow coma scale used in veterinary 
medicine (Platt, Radaelli, and McDonnell 2001; Table 1). The veterinary modified Glasgow coma scale was first adapted from human medicine in 1983, and assigns scores for various sets of clinical neurologic abnormalities to monitor patient progression and determine overall prognosis (Platt, Radaelli, and McDonnell 2001; Shores 1983). The neurobehavioral assessment included mentation, responsiveness to external stimulation, ability to ambulate, quantity and quality of movement, muscle tremors, and respiratory effort (Table 1, Supplemental material).

The research facilities precluded the researchers from being blinded. However, both investigators observed all birds in each group, treatment group was not confirmed prior to assigning a clinical severity score, and investigators adhered to the defining characteristics of each score. Birds were monitored for neurobehavioral signs every 5 to $10 \mathrm{~min}$

Table 1. Clinical severity scores ${ }^{a}$.

\begin{tabular}{|c|c|}
\hline Severity score & Neurobehavioral abnormalities \\
\hline $0=$ Normal & - No clinical signs \\
\hline $1=$ Mild & $\begin{array}{l}\text { - Mildly sedate but remains standing } \\
\text { - May lie down briefly but quickly stands when } \\
\text { stimulated } \\
\text { - Readily returns to normal behavior with external } \\
\text { stimulation }\end{array}$ \\
\hline $2=$ Moderate & $\begin{array}{l}\text { - Moderate sedation, appears to be sleeping but } \\
\text { with abnormal roosting posture (i.e. head } \\
\text { down on the ground instead of tucked behind } \\
\text { wing) } \\
\text { - Consistently lying down } \\
\text { - Displaying piloerection } \\
\text { - Eyes partially closed or glassy-eyed } \\
\text { - May demonstrate ataxia } \\
\text { - May have intermittent, generalized muscle } \\
\text { tremors } \\
\text { - Mildly increased respiratory effort } \\
\text { stimical signs improve to mild with external } \\
\text { behavior but does not return to normal }\end{array}$ \\
\hline $3=$ Severe & $\begin{array}{l}\text { - Clinical signs as noted in moderate but more } \\
\text { - Severe } \\
\text { - Severe sedation, minimally response to external } \\
\text { stimulation } \\
\text { - More consistent whole-body tremors } \\
\text { - More severe ataxia } \\
\text { - Unable to stand or ambulate on own }\end{array}$ \\
\hline $4=$ Comatose & $\begin{array}{l}\text { - Severe sedation, non-responsive to external } \\
\text { stimulation } \\
\text { - More consistent whole-body tremors } \\
\text { - Laterally recumbent, unable to stand } \\
\text { - Occasional regurgitation }\end{array}$ \\
\hline
\end{tabular}

${ }^{a}$ Classification system for the clinical severity scores used to categorize the severity of neurobehavioral abnormalities observed after oral administration of imidacloprid in domestic chickens. immediately after gavage, then hourly once the most severe neurobehavioral signs were reached and birds began to recover. Birds received one clinical severity score on each exposure day indicating the most severe neurobehavioral signs displayed that day. The time from gavage to onset of any neurobehavioral signs and approximate duration of neurobehavioral signs from the time of onset to complete resolution of signs were recorded in min.

\section{Immune function assays}

Multiple immune function assays were performed to evaluate components of both the innate and adaptive immune system (Fairbrother, Smits, and Grasman 2004; Grasman 2010). Assays were selected from both tier I and II of the National Toxicology Program guidelines for immunotoxicity. These assays provide data regarding the in vivo function of several arms of the immune system at sublethal toxicant exposures and help to assess overall immune function, especially when used in combination (Fairbrother, Smits, and Grasman 2004; Luster et al. 1993, 1992).

\section{Complete blood counts}

Blood was sterilely collected into a heparinized syringe within $3 \mathrm{~min}$ of manual restraint, prior to all other procedures, in order to minimize the effects of stress on the results. Packed cell volume (PCV) and buffy coat (BC) \% were measured using heparinized hematocrit tubes. Total solids (TS) were measured with a calibrated refractometer. Estimated total white blood cell (WBC) counts were performed manually with a blood smear (Campbell and Ellis 2007). All blood smears were read by the same experienced technician in no particular order without knowledge of the exposure group. Long-term stress produces immunosuppression, and is reflected by an increase in the $\mathrm{H} / \mathrm{L}$ ratio and total WBC count (Gross and Siegel 1983).

\section{Microbiocidal assay}

The microbiocidal assay measures the ability of the innate immune system to kill a known quantity of Escherichia coli, Staphylococcus aureus, and Candida albicans (French and Neuman-Lee 2012). The methodology was as published in French and Neuman-Lee (2012) with the following modifications. Blood was 
sterilely collected into a heparinized syringe, plasma was separated into aliquots and stored at $-80^{\circ} \mathrm{C}$ until analysis. Thawed plasma was diluted 1:3 in phosphate buffered saline for $S$. aureus and C. albicans. Plasma was diluted 1:5 in $\mathrm{CO}_{2}$ independent media for E. coli. Tryptic soy broth was added to all wells at a 1:8 dilution for S. aureus and C. albicans, and a 1:6 dilution for E. coli. The microbiocidal ability of plasma is reported as \% microorganisms killed by the plasma, calculated as follows: (1 - sample mean absorbance/positive control mean absorbance) x 100 .

The S. aureus and C. albicans analyses were performed 6 to 9 wk after sample collection. S. aureus and C. albicans results are not available from the first batch of birds ( $\mathrm{n}=5$ from the $0.03,0.34,3.42$, and $10.25 \mathrm{mg} / \mathrm{kg} / \mathrm{d}$ groups, and $\mathrm{n}=4$ from $0 \mathrm{mg} / \mathrm{kg} / \mathrm{d}$ ) because the plasma samples were degraded from freezer storage when the assay methodology was validated, and the results were no longer comparable to the other batches. The E. coli analysis was performed 12 to 13 months after sample collection and was staged so that all samples were stored for the same duration of time prior to analysis.

\section{Sheep red blood cell hemagglutination and hemolysis}

The SRBC hemagglutination and hemolysis assay evaluates the ability of B-lymphocytes to generate a primary, antigen-specific antibody response after a single exposure to a novel antigen, and the ability of natural and acquired antibodies to initiate SRBC lysis via the complement cascade (Costabile 2010; Grasman 2002, 2010; Matson et al., 2005). The SRBCs were processed according to Grasman (2010). The hemagglutination and hemolysis methodology was conducted according to Matson, Ricklefs, and Klasing (2005) with the following modifications. Blood was sterilely collected into a heparinized syringe; plasma was separated into aliquots and stored at $-80^{\circ} \mathrm{C}$ until analysis. The same vial of $50 \%$ whole sheep blood and Alsever solution (Colorado Serum Company, product \# 31113) that was employed for injection into an individual chicken was utilized for the benchtop assay for that bird to ensure that the antigen profile of the SRBCs was identical. Birds were injected with $0.1 \mathrm{ml}$ $20 \%$ SRBC solution into the left pectoral muscle.
Thawed, unheated plasma was serially diluted 1:2 for agglutination titers, resulting in dilutions from $1: 2$ to $1: 2048$. Samples were run in duplicate on separate plates. A $1 \%$ SRBC solution was added to all wells at a 1:3 dilution. The final agglutination titer was expressed as $\log _{2}$ of the mean reciprocal titer. All plates were scored by one researcher.

The hemolysis results are expressed as the plasma dilution required to produce $50 \%$ lysis of the SRBCs $\left(\mathrm{CH}_{50}\right)$. The $\mathrm{CH}_{50}$ for each sample was calculated as in Costabile (2010) and the results were averaged between duplicate plates. The background absorbance of plasma was read at $405 \mathrm{~nm}$ prior to adding SRBCs to the plate and was subtracted from the final absorbance of the supernatant measured after the last incubation period. The $\%$ lysis of each well was calculated using the following formula: (\% lysis = sample absorbance/mean absorbance of the positive controls) $\mathrm{x} 100$.

\section{Phytohemagglutinin-A}

The PHA response is primarily an adaptive immune response orchestrated by T-lymphocytes, however the innate immune system contributes to the inflammation measured as the skin swelling (Grasman 2002, 2010; Martin et al. 2006; Smits, Bortolotti, and Tella 1999). The procedure for the PHA test was based upon avian protocols (Grasman 2010; Smits, Bortolotti, and Tella 1999). Feathers were plucked from an approximately $1 \mathrm{~cm}$ diameter area on the left patagium $48 \mathrm{~h}$ prior to the test to enable any inflammation associated with feather removal to resolve. The patagial thickness in the plucked area was measured to the nearest $0.01 \mathrm{~mm}$ using a digital micrometer. Three measurements were taken with approximately 50\% location overlap and averaged. PHA $(0.1 \mathrm{mg})$ was injected subcutaneously (sc) and the injection site was marked with a permanent marker. The skin thickness was measured approximately $24 \mathrm{~h}( \pm 3-4 \mathrm{~h})$ after the PHA injection via the same method. All measurements were taken by the same investigator. The immune response is measured as the amount of swelling after PHA injection, presented as 
follows: post-PHA injection measurement - prePHA injection measurement.

\section{Delayed type hypersensitivity}

The DTH test requires interaction between components of both the innate and adaptive immune system to assess the ability of the bird to produce antigen specific memory $\mathrm{T}$-cells in response to Mycobacterium tuberculosis in Freund's complete adjuvant (FCA), a slow release medium that enhances Th1 CD4 + T-lymphocyte response (Billiau and Matthys 2001; Dietert, Bunn, and Lee 2010; El-Lethey, Huber-Eicher, and Jungi 2003). Two weeks after the initial injection, birds were injected with tuberculin purified protein derivative (PPD), which stimulates a complex cascade of immune responses involving CD8 $+\mathrm{T}$ cells, CD4 + T cells, and cytokines, resulting in a type IV hypersensitivity reaction and a measurable skin swelling (El-Lethey, Huber-Eicher, and Jungi 2003; Grasman 2010). The methodology was modified from El-Lethey, Huber-Eicher, and Jungi (2003). Chickens were injected sc over the right pectoral muscle with $0.5 \mathrm{mg}$ of dead Mycobacterium tuberculosis $(\mathrm{H} 37 \mathrm{Ra})$ in FCA. The baseline thickness of the interdigital skin web between digits 3 and 4 was measured to the nearest $0.01 \mathrm{~mm}$ on both feet using a digital micrometer. Three measurements were taken with at least $50 \%$ location overlap and averaged. An intradermal injection of $0.1 \mathrm{~mL}$ of PPD diluted 1:1 with sterile saline was given in the right interdigital skin web. The same procedure was repeated on the left foot with $0.2 \mathrm{ml}$ sterile saline as a negative control. The thickness of both interdigital skin webs was measured $24 \mathrm{~h}( \pm 3-4 \mathrm{~h})$ later via the same method by the same researcher. The results are expressed as follows: (mean post-PPD injection measurement/mean pre-PPD injection measurement) (mean post-saline injection measurement/mean presaline injection measurement).

\section{Necropsy}

Birds were humanely euthanized with an intravenous (iv) injection of euthanasia solution ( $1 \mathrm{ml}$, $390 \mathrm{mg} / \mathrm{ml}$ pentobarbital sodium, $50 \mathrm{mg} / \mathrm{ml}$ phenytoin). A complete gross postmortem examination was performed on all birds within $5 \mathrm{~h}$ of euthanasia. Sex was confirmed. Any gross abnormalities were recorded, including location and severity. Samples from all gross lesions noted at necropsy were preserved in formalin for histopathology. Microbiology samples were aseptically collected from a subset of lesions. Organ weights were obtained for the spleen, thymus, bursa of Fabricius, liver, kidney and brain, and expressed as $\%$ bird body weight at the time of euthanasia.

\section{Statistical methods}

The mean clinical severity score, time (min) until onset of neurobehavioral signs, and duration of neurobehavioral signs (min) were calculated for each individual bird over the duration of the exposure period (day 0-6). The mean value for each individual was used to calculate the treatment group means, which were compared between groups with a Kruskal-Wallis test. All birds were included in the treatment group mean clinical severity score and duration of neurobehavioral sign calculations, including birds with clinical severity scores of 0 and duration values of $0 \mathrm{~min}$. Only birds that developed neurobehavioral signs were included in the treatment group mean time until onset of neurobehavioral signs. T-tests were used to compare clinical severity scores and duration of neurobehavioral signs between sexes within the 3.42, 10.25 or $15.5 \mathrm{mg} / \mathrm{kg} / \mathrm{d}$ groups. The correlation between the individual bird mean clinical severity score and individual mean duration of neurobehavioral signs was analyzed with linear regression. To evaluate change in individual clinical severity scores and duration of neurobehavioral signs over time, a linear regression line was fitted for each individual bird and the slope was a representation of the manner in which an individual changed over time. A Wilcoxon signed-rank test was performed within each treatment group to test if the slope values were significantly different from zero. A KruskalWallis test was performed to compare the mean slope between treatment groups.

The no observed effect level (NOEL), no observed adverse effect level (NOAEL), lowest observed effect level (LOEL) and lowest observed adverse effect level (LOAEL) were based upon statistically significant differences between treatment groups using both the daily and the 
individual mean clinical severity scores. An adverse effect was defined as a clinical severity score of moderate or higher. A mild clinical severity score was not considered adverse as the birds were rousable to normal behavior. The effect dose values where $50 \%\left(\mathrm{ED}_{50}\right)$ and $10 \%\left(\mathrm{ED}_{10}\right)$ of the population was affected were determined by fitting the observed neurobehavioral signs with a 4 parameter log-logistic dose response model using the 'drc' package in R 3.4.3 open-source environment (Ritz et al. 2015). The clinical severity scores were adjusted via 2 methods for this analysis: presence of any neurobehavioral signs where 0 indicated no neurobehavioral signs and 1 indicated any type of neurobehavioral sign, and an adjusted score, calculated as the log of duration of neurobehavioral signs multiplied by the square root of the observed clinical severity score.

Weekly weight gain was compared between treatment groups via an analysis of covariance (ANCOVA) for each time interval. Sex was included as a covariate because males had a higher growth rate than females. Mean crop size was compared between treatment groups via a one-way analysis of variance (ANOVA) on each exposure day. Spearman rank-order correlation was used to assess if there was a monotonic relationship between crop size and clinical severity score. The immune function assays with one data point were analyzed via a one-way ANOVA or Kruskal-Wallis test. Continuous data with repeated measurements within an individual bird were analyzed with a linear-mixed model with batch and chicken id as random effects. Differences in light cycle were accounted for by including batch in all final models. Sex and age were evaluated as potential confounding variables using an ANOVA and were included in models where they may have had a statistically significant and biologically relevant effect on the results. Pairwise comparisons with a Tukey's correction were performed to assess the source of significant $p$ values in the linear-mixed model. A power analysis was performed for the PHA, DTH, and SRBC hemagglutination and hemolysis assays and all had a statistical power of $\geq 80 \%$ with a significance level of 0.05. An alpha level of 0.05 was used for significance. All statistical analyses were performed using $\mathrm{R}$ open-source environment versions 1.2.1335 and 3.4.3 (R Core Team 2018).

\section{Results}

\section{Chemical confirmation}

The purity and concentrations of the oral exposure suspensions reported in the methods were confirmed using HPLC. Neonicotinoids were not detected in either the feed or the grain-based gavage feeding formula. The minimum detection and quantification limits for the method were 0.1 and $0.3 \mathrm{ng} / \mathrm{g}$, respectively.

\section{Neurobehavioral abnormalities}

All birds were neurologically normal throughout the acclimation period and the duration of the study unless exposed to oral imidacloprid. Neurobehavioral abnormalities were only observed after oral imidacloprid exposure, and all birds returned to normal prior to the subsequent dose. No neurobehavioral abnormalities were noted in the 0 or $0.03 \mathrm{mg} / \mathrm{kg} / \mathrm{d}$ birds at any point during the study. Only one bird developed neurobehavioral signs in the $0.34 \mathrm{mg} / \mathrm{kg} / \mathrm{d}$ group, exhibiting mild signs on days 1 and 2 , with a mean \pm standard deviation of $65 \pm 49.5$ min until onset and a mean duration of $45 \pm 21.2 \mathrm{~min}$. The treatment group prevalence of any type of neurobehavioral signs at any point during the study, calculated as the number of days when a bird exhibited any neurobehavioral signs divided by the total days of imidacloprid exposure, was $1.4 \%$ of $0.34 \mathrm{mg} / \mathrm{kg} /$ d, $30 \%$ of $3.42 \mathrm{mg} / \mathrm{kg} / \mathrm{d}, 92.9 \%$ of $10.25 \mathrm{mg} / \mathrm{kg} / \mathrm{d}$, and $98.6 \%$ of $15.5 \mathrm{mg} / \mathrm{kg} / \mathrm{d}$ birds. The prevalence of neurobehavioral abnormalities was significantly different between treatment groups. All $15.5 \mathrm{mg} /$ $\mathrm{kg} / \mathrm{d}$ birds developed neurobehavioral signs on every day of exposure except for days 3 and 6 , when a single female bird remained clinically normal each of these days; a different bird remained normal each day.

Birds exhibited a gradient of neurobehavioral signs each day of exposure. Neurobehavioral signs started with mild abnormalities, increased in severity to the most severe signs exhibited that day, then gradually 
decreased in severity until returning to normal. The mean time until onset of clinical signs \pm standard deviation was $26 \pm 12.5 \mathrm{~min}$ for $3.42 \mathrm{mg} / \mathrm{kg} / \mathrm{d}$ group, $19.2 \pm 10.9 \mathrm{~min}$ for $10.25 \mathrm{mg} / \mathrm{kg} / \mathrm{d}$ group, and $12.6 \pm 3.7 \mathrm{~min}$ for $15.5 \mathrm{mg} / \mathrm{kg} / \mathrm{d}$ group. Despite the inverse relationship between time until onset and dose, a marked difference in the time until onset of neurobehavioral signs was not detected between groups. The most rapid onset of neurobehavioral signs was noted 3 min post-gavage in a female $10.25 \mathrm{mg} / \mathrm{kg} / \mathrm{d}$ and a male $3.42 \mathrm{mg} / \mathrm{kg} / \mathrm{d}$ bird.

Severely affected animals with a clinical severity score of 4 in the high-dose group were unable to ambulate normally due to ataxia and generalized muscle tremors, were completely non-responsive to their surroundings, and these signs persisted for as long as $5.5 \mathrm{~h}$ (Supplemental material). The mean clinical severity score for the 10.25 and
$15.5 \mathrm{mg} / \mathrm{kg} / \mathrm{d}$ treatment groups was higher than all other groups (Figure 1, supplemental material Table S2). Males within the 10.25 and $15.5 \mathrm{mg} / \mathrm{kg} /$ $\mathrm{d}$ treatment groups had higher mean clinical severity scores compared to females within the same group, and the disparity between sexes rose significantly in the higher exposure group. The mean slope of the clinical severity scores declined over the exposure period within the $15.5 \mathrm{mg} / \mathrm{kg} / \mathrm{d}$ group, and this relationship was driven by females (Table 2). The only difference in the clinical severity slope when the sexes were combined was between the 10.25 and $15.5 \mathrm{mg} / \mathrm{kg} / \mathrm{d}$ groups. No marked differences were detected in the mean clinical severity slope between treatment groups in males. In females, the clinical severity slope in the $15.5 \mathrm{mg} / \mathrm{kg} / \mathrm{d}$ group was significantly lower than $10.25 \mathrm{mg} / \mathrm{kg} / \mathrm{d}$ group.
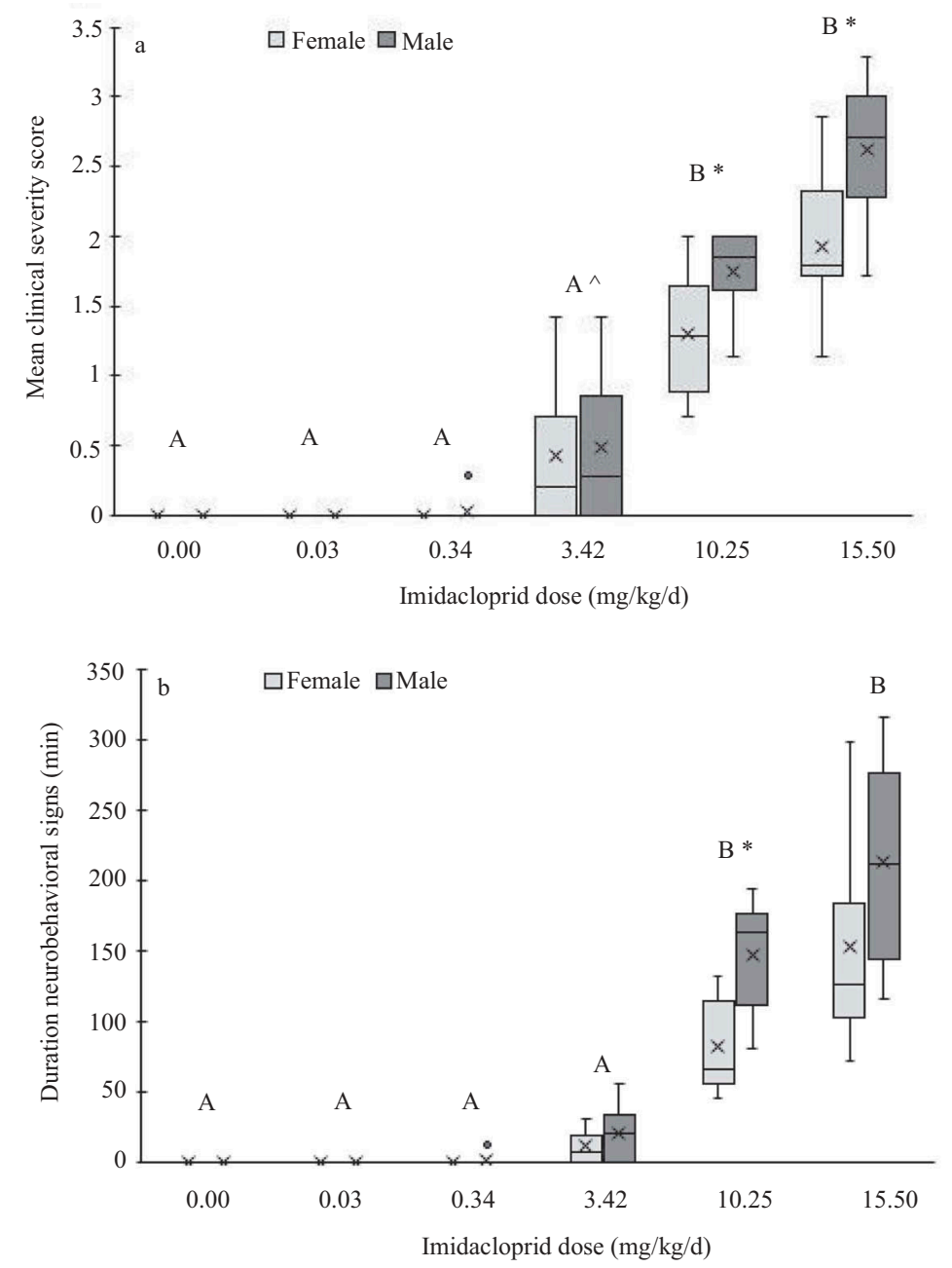

Figure 1. Box and whisker plot depicting the mean clinical severity score and the mean duration of neurobehavioral signs in domestic chickens after oral imidacloprid exposure by treatment group and sex. 
Table 2. Mean clinical severity score and duration of neurobehavioral signs slopes by treatment group ${ }^{\mathrm{a}}$.

\begin{tabular}{|c|c|c|c|c|c|c|}
\hline & \multicolumn{3}{|c|}{ Clinical severity scores (points/d) } & \multicolumn{3}{|c|}{ Duration neurobehavioral signs $(\mathrm{min} / \mathrm{d})$} \\
\hline & Slope both sexes & Slope males & Slope females & Slope both sexes & Slope males & Slope females \\
\hline \multicolumn{7}{|c|}{ Imidacloprid dose } \\
\hline $0.00 \mathrm{mg} / \mathrm{kg} / \mathrm{d}$ & $0.00 \pm 0.00$ & $0.00 \pm 0.00$ & $0.00 \pm 0.00$ & $0.00 \pm 0.00$ & $0.00 \pm 0.00$ & $0.00 \pm 0.00$ \\
\hline $0.03 \mathrm{mg} / \mathrm{kg} / \mathrm{d}$ & $0.00 \pm 0.00$ & $0.00 \pm 0.00$ & $0.00 \pm 0.00$ & $0.00 \pm 0.00$ & $0.00 \pm 0.00$ & $0.00 \pm 0.00$ \\
\hline $0.34 \mathrm{mg} / \mathrm{kg} / \mathrm{d}$ & $-0.01 \pm 0.02$ & $-0.01 \pm 0.03$ & $0.00 \pm 0.00$ & $-0.27 \pm 1.20$ & $-0.54 \pm 1.69$ & $0.00 \pm 0.00$ \\
\hline $3.42 \mathrm{mg} / \mathrm{kg} / \mathrm{d}$ & $-0.07 \pm 0.15$ & $-0.04 \pm 0.11$ & $-0.10 \pm 0.18$ & $-0.42 \pm 4.69$ & $-0.30 \pm 5.05$ & $-0.54 \pm 4.57$ \\
\hline $10.25 \mathrm{mg} / \mathrm{kg} / \mathrm{d}$ & $-0.01 \pm 0.08$ & $-0.01 \pm 0.07$ & $-0.01 \pm 0.09$ & $1.46 \pm 12.67$ & $-1.11 \pm 12.90$ & $4.03 \pm 12.54$ \\
\hline $15.50 \mathrm{mg} / \mathrm{kg} / \mathrm{d}$ & $-0.10 \pm 0.10^{* \wedge}$ & $-0.05 \pm 0.08$ & $-0.15 \pm 0.10^{\wedge}$ & $-6.55 \pm 9.51^{*}$ & $-2.33 \pm 10.09$ & $-10.76 \pm 7.05^{*} \sim$ \\
\hline
\end{tabular}

${ }^{\mathrm{a} A}$ linear regression line was fitted for the clinical severity scores and the change in duration of neurobehavioral signs in each individual domestic chicken after oral imidacloprid exposure over the 7 day exposure period. The slope of the liner regression line was a representation of how an individual changed over time. The individual bird slope values were used to calculate a treatment group mean slope \pm standard deviation of the clinical severity scores and duration of neurobehavioral signs. The treatment group mean slope is presented in this table. A Wilcoxon signed-rank test was performed within each treatment group to test if the slope values were significantly different from zero. A Kruskal-Wallis test was performed to compare the mean slope between treatment groups.

*Slope was significantly different from zero $p \leq 0.05$

$\wedge$ Slope is significantly different than the $10.25 \mathrm{mg} / \mathrm{kg} / \mathrm{d}$ group $p \leq 0.05$

$\sim$ Slope is significantly different than the 3.42 and $10.25 \mathrm{mg} / \mathrm{kg} / \mathrm{d}$ groups $p \leq 0.05$

The mean duration of neurobehavioral signs increased in a dose-dependent manner, with the duration of neurobehavioral signs in the 10.25 and $15.5 \mathrm{mg} / \mathrm{kg} / \mathrm{d}$ groups being significantly longer than all other groups (Figure 1, supplemental material Table S2). The 10.25 and $15.5 \mathrm{mg} / \mathrm{kg} / \mathrm{d}$ treatment groups did not differ markedly from each other, nor did the $3.42 \mathrm{mg} / \mathrm{kg} / \mathrm{d}$ treatment group differ from the $0,0.03$, or $0.34 \mathrm{mg} / \mathrm{kg} / \mathrm{d}$ groups. The mean duration of neurobehavioral signs was significantly longer in males than females within the $10.25 \mathrm{mg} / \mathrm{kg} / \mathrm{d}$ group only. The mean slope of the duration of neurobehavioral signs declined within the $15.5 \mathrm{mg} / \mathrm{kg} / \mathrm{d}$ treatment group, and this change was driven by females (Table 2). When the sexes were combined none of the comparisons between treatment groups were significant. When separated by sex, no significant differences in slope were detected between treatment groups in males. In females, the mean slope in the $15.5 \mathrm{mg} / \mathrm{kg} / \mathrm{d}$ group was significantly lower than the 3.42 and $10.25 \mathrm{mg} / \mathrm{kg} / \mathrm{d}$ groups. A linear regression confirmed a correlation between a higher individual mean clinical severity score and a longer individual mean duration of neurobehavioral signs (Figure 2).

Severity of neurobehavioral signs within an individual bird varied from one exposure day to the next in the $3.42,10.25$, and $15.5 \mathrm{mg} / \mathrm{kg} / \mathrm{d}$ groups. For example, one male $15.5 \mathrm{mg} / \mathrm{kg} / \mathrm{d}$ bird displayed a clinical severity score of 2 on day 1 , a score of 4 on day 2 and 3, and then returned to a score of 2 on day 4 . No clear pattern existed in the variability of the clinical severity score within an individual bird between exposure days, and the unpredictability in clinical severity score did not appear related to exposure dose. The variability may have been related to gastrointestinal contents as represented by crop size, but this was not the only explanatory factor. Age exerted no detectable effect on the observed neurobehavioral abnormalities.

\section{Weight gain and crop size}

The mean weekly weight gain from day 0 to 7 in the $15.5 \mathrm{mg} / \mathrm{kg} / \mathrm{d}$ group was nearly $50 \%$ lower than the other groups (Figure 3). After cessation of imidacloprid exposure, the mean weekly weight gain from days 7 to 14 in the $15.5 \mathrm{mg} / \mathrm{kg} / \mathrm{d}$ group was approximately $25 \%$ greater than the other groups. No other differences in weekly weight gain, or in the mean total weight gain from day 0 to 21 , were detected between treatment groups. Age did not exert a detectable effect on weekly weight gain.

The crop size in the $15.5 \mathrm{mg} / \mathrm{kg} / \mathrm{d}$ group was significantly larger on days 4 and 5 (mean score \pm standard deviation; $2.2 \pm 1.0$ and $2.1 \pm 0.9$ respectively) compared to $0,0.03,0.34$, and $3.42 \mathrm{mg} / \mathrm{kg} / \mathrm{d}$ groups. The crop size in the $15.5 \mathrm{mg} / \mathrm{kg} / \mathrm{d}$ group was significantly larger on day $1(2.1 \pm 0.8)$ compared to 0 , 3.42 , and $10.25 \mathrm{mg} / \mathrm{kg} / \mathrm{d}$ groups. On day 6 , crop size in the $10.25 \mathrm{mg} / \mathrm{kg} / \mathrm{d}$ group was significantly greater $(1.8 \pm 0.8)$ compared to $0 \mathrm{mg} / \mathrm{kg} / \mathrm{d}$ group $(0.9 \pm 0.7)$ 


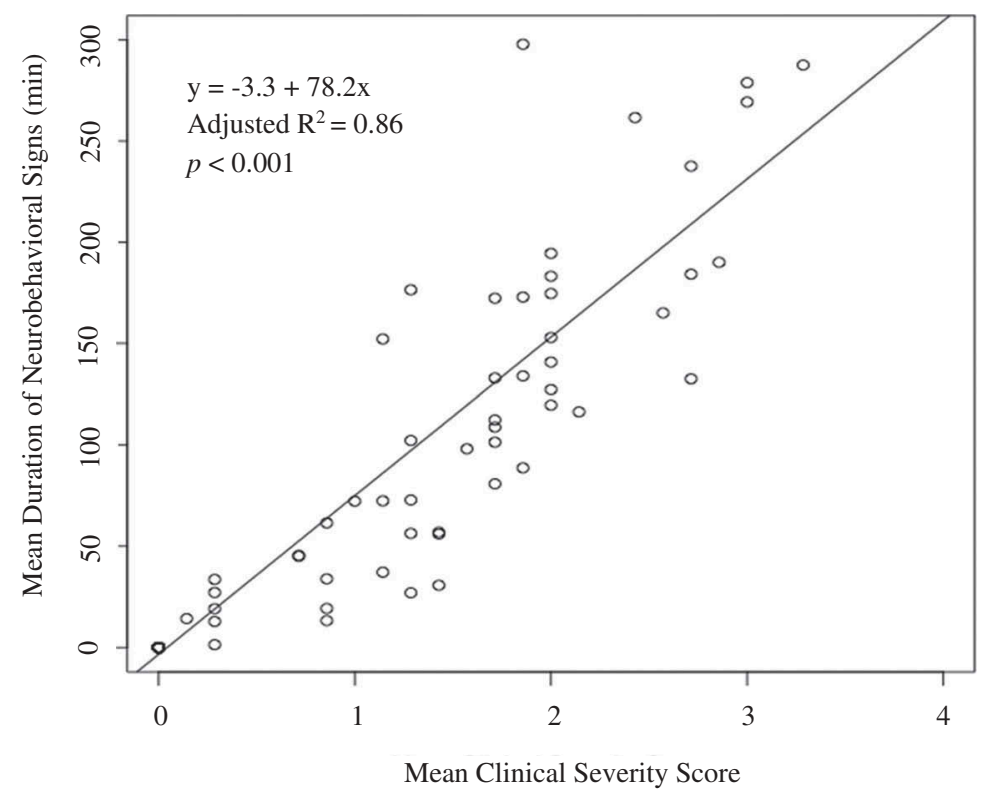

Figure 2. Linear regression plot using the mean clinical severity score (scale 0-4) as the predictor and mean duration (min) of neurobehavioral signs for each chicken after oral imidacloprid exposure as the outcome variable.

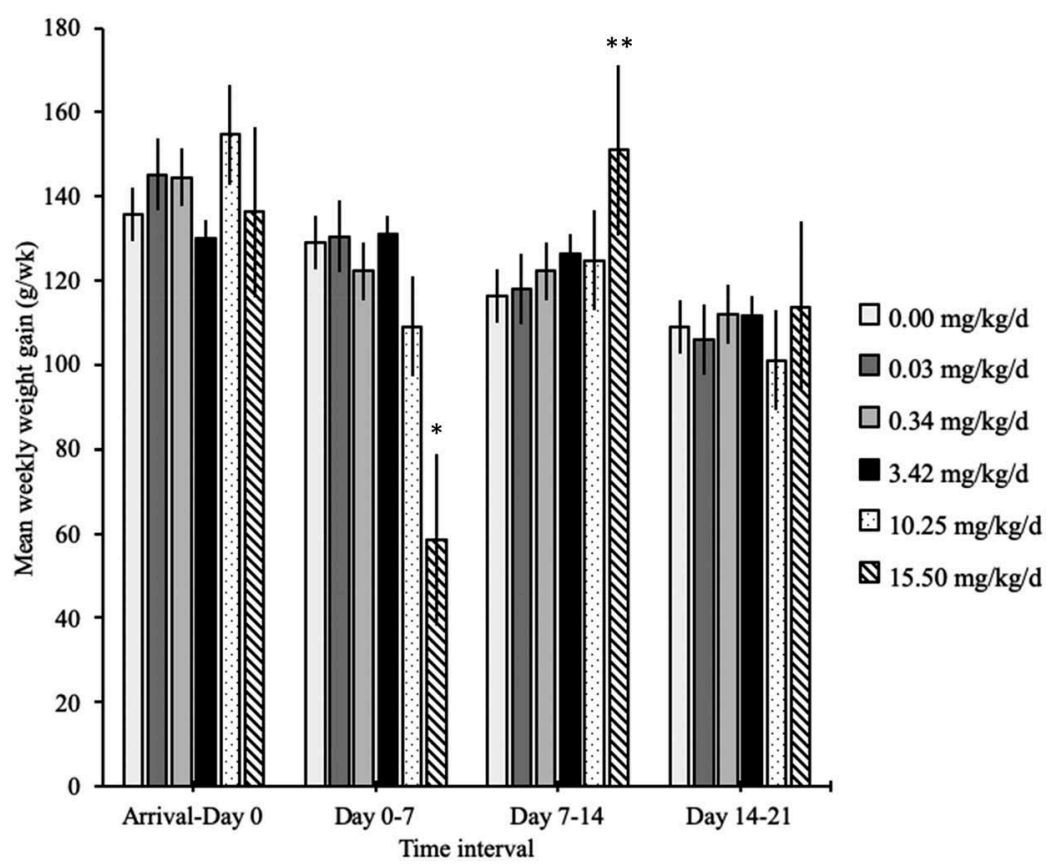

Figure 3. Mean weekly weight gain ( \pm standard error) of domestic chickens in each imidacloprid exposure group in grams per week (g/wk); birds were exposed to imidacloprid from day 0 to 6; statistically significant differences between treatment groups each week are noted with asterisks.

* Significantly decreased weight gain in the $15.50 \mathrm{mg} / \mathrm{kg} / \mathrm{d}$ group compared to all other treatment groups . ${ }^{*}$ Significantly increased weight gain in the $15.50 \mathrm{mg} / \mathrm{kg} / \mathrm{d}$ group compared to all other treatment groups

\section{Effect levels}

The observed effect levels using the daily clinical severity scores for each exposure day were similar to those calculated using the individual mean clinical severity score. The NOEL was $0.34 \mathrm{mg} / \mathrm{kg} / \mathrm{d}$, meaning the highest dose where no neurobehavioral effects were observed. The NOAEL and LOEL were $3.42 \mathrm{mg} / \mathrm{kg} / \mathrm{d}$, meaning the lowest dose where neurobehavioral abnormalities were observed, and the lowest dose where neurobehavioral abnormalities 
were within the mild clinical severity-score category and were not considered adverse. Mild neurobehavioral abnormalities were not considered adverse as the birds were rousable to normal behavior. The LOAEL was $10.25 \mathrm{mg} / \mathrm{kg} / \mathrm{d}$, meaning the lowest dose where neurobehavioral abnormalities with moderate clinical severity scores were noted. These neurobehavioral abnormalities were considered adverse as the birds were depressed, unable to ambulate normally, and were not rousable to normal behavior. The dose-response curves for the presence of any neurobehavioral signs and the adjusted scores increased rapidly beginning at imidacloprid doses of $3.42 \mathrm{mg} / \mathrm{kg} / \mathrm{d}$ (Figure 4). The $\mathrm{ED}_{10}$ ( \pm standard error of the mean) for the presence of any neurobehavioral signs was $2.19 \pm 0.51 \mathrm{mg} / \mathrm{kg} / \mathrm{d}$, and the $\mathrm{ED}_{50}$ was $4.62 \pm 0.98 \mathrm{mg} / \mathrm{g} / \mathrm{d}$. The $\mathrm{ED}_{10}$ for the adjusted score was $2.54 \pm 0.88 \mathrm{mg} / \mathrm{kg} / \mathrm{d}$, and the $\mathrm{ED}_{50}$ was $11.24 \pm 9.33 \mathrm{mg} / \mathrm{kg} / \mathrm{d}$.

\section{Immune function assays}

\section{Complete blood counts}

Batch and sex did not markedly influence the CBC parameters. Final linear-mixed models for PCV and TS included age. Mean PCV did not differ significantly between treatment groups at any time point. On day 0 , the mean TS in the $15.5 \mathrm{mg} / \mathrm{kg} / \mathrm{d}$ group was significantly lower than the 0.03 and $10.25 \mathrm{mg} /$ $\mathrm{kg} / \mathrm{d}$ groups (supplemental material Table S1). No other differences in TS were detected. The mean TS within all groups rose over time and was reflected by the significant treatment group and time interaction.

The total WBC count was elevated significantly from day 0 to 21 in all treatment groups (supplemental material Table S1) except control. The H/L ratio increased from day 0 to 21 within all groups (supplemental material Table S1), except control and $15.5 \mathrm{mg} / \mathrm{kg} / \mathrm{d}$ groups. The rise in $\mathrm{H} / \mathrm{L}$ ratio started after day 7 in all treatment groups. The mean total $\mathrm{WBC}$ count and $\mathrm{H} / \mathrm{L}$ ratio did not differ significantly between treatment groups on any of the sampling days.

\section{Other immune function assays}

The linear-mixed model for $S$. aureus, $C$. albicans and E. coli did not include sex or age. The mean \% killing of S. aureus, E. coli and C. albicans did not differ significantly between treatment groups on any of the sampling dates but did change within treatment groups over time (Figure 5). The \% killing of $S$. aureus gradually significantly increased from day 0 to 21 within the $3.42 \mathrm{mg} / \mathrm{kg} / \mathrm{d}$ group and from day 3 to 21 in the $10.25 \mathrm{mg} / \mathrm{kg} / \mathrm{d}$ group. The $\%$ killing of $E$. coli was decreased by $17 \%$ from day 0 to 14

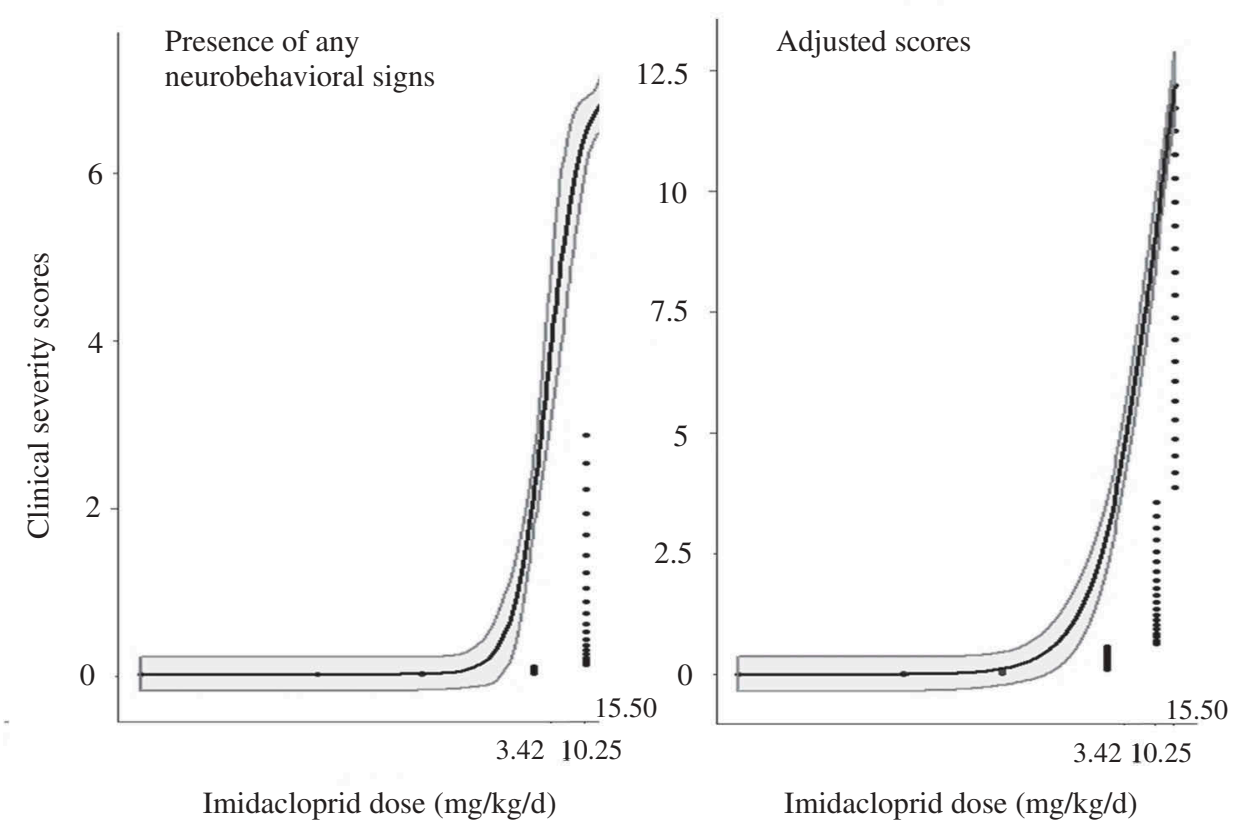

Figure 4. Effect dose (ED) dose-response curves of neurobehavioral abnormalities observed in domestic chickens after oral imidacloprid exposure using two variables: the presence of any neurobehavioral signs and the adjusted clinical severity score. 

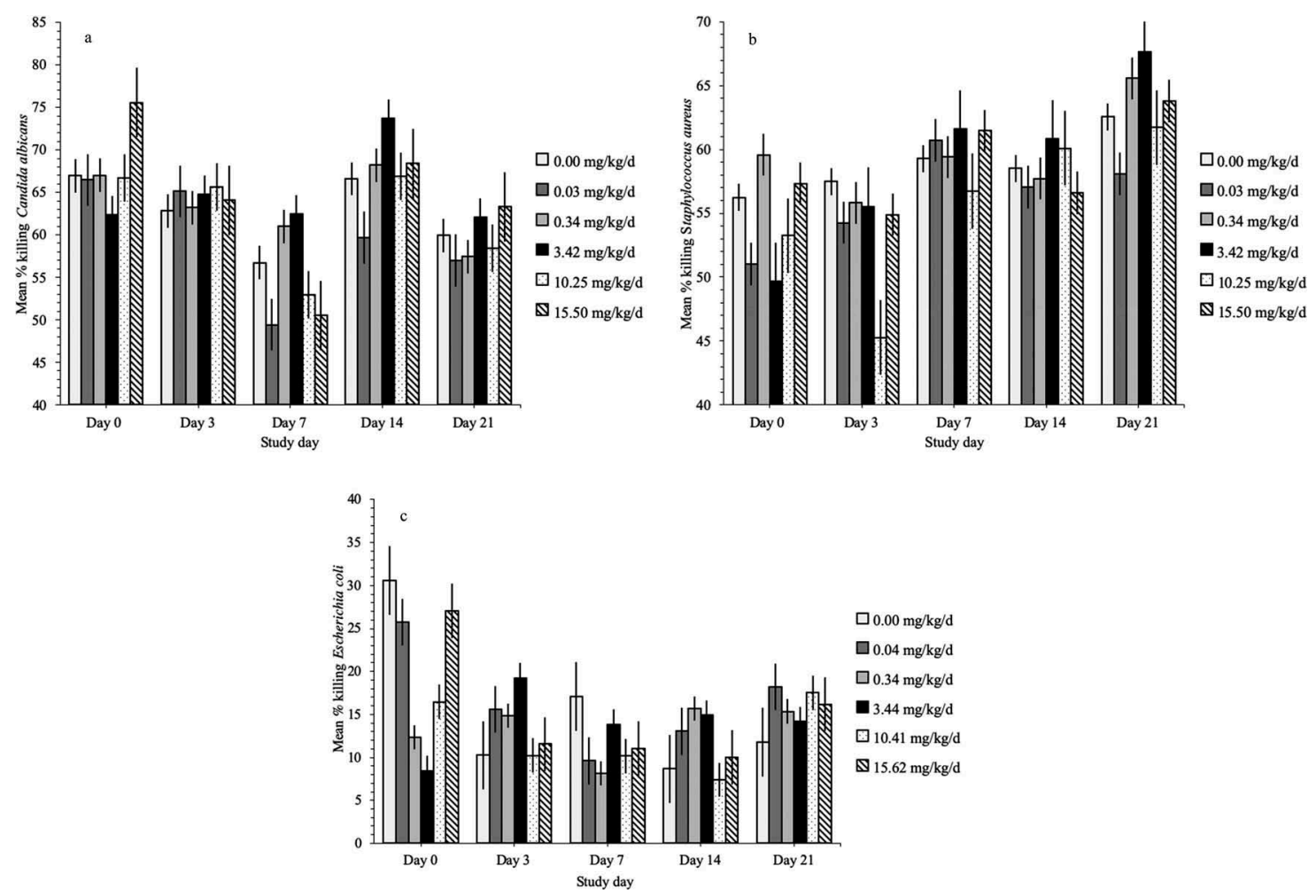

Figure 5. Mean percent killing by treatment group of each microorganism ( \pm standard error) on each sampling date in domestic chickens exposed to oral imidacloprid (day 0-6). Candida albicans is in (a), Staphylococcus aureus in (b), and Escherichia coli in (c). There were no statistically significant differences between treatment groups.

in the $15.5 \mathrm{mg} / \mathrm{kg} / \mathrm{d}$ group. The \% killing of C. albicans fell significantly from day 0 to 7 in the $0.03,10.25$ and $15.5 \mathrm{mg} / \mathrm{kg} / \mathrm{d}$ groups and then increased toward baseline levels on day 14. Mean SRBC agglutination titers, $\mathrm{CH}_{50}$ hemolysis titers, PHA response, and DTH response did not differ markedly between treatment groups (Table 3).

\section{Necropsy}

Organ weights did not differ significantly between treatment groups (Table 3). Brain weight was consistently 2 to $3 \mathrm{~g}$. All birds, including the control and exposure groups, developed multifocal mass lesions overlying the right pectoral muscle at the injection site of FCA. The lesions contained caseous debris encapsulated by fibrous tissue with varying degrees of associated vascular formation. Lesion samples from 3 individuals were negative for bacterial growth via aerobic and anaerobic culture. Six lesion samples were analyzed via histopathology, one sample from each treatment group. The mass lesions were diagnosed as chronic, multifocal, sterile granulomatous cellulitis, consistent with adjuvant induced granulomas (Yamanaka et al. 1993). The severity of abscess formation was not correlated with treatment group, batch, sex or age. No other abnormalities were noted on gross necropsy.

\section{Discussion}

Chickens developed dose-dependent, temporary neurobehavioral abnormalities after oral imidacloprid exposure. While the neurobehavioral signs were comparable to those observed in birds in field and lab settings (Addy-Orduna, Brodeur, and Mateo 2019; Eng, Stutchbury, and Morrissey 2017, 2019; Millot et al. 2017), the effects were precisely documented in a doseresponse study which enabled determination of effect dose levels. The nervous system appeared to be a more sensitive indicator of sublethal effects than the immune system, as immunotoxicity was not detected. 
Table 3. Immunologic and necropsy results ${ }^{\mathrm{a}}$.

\begin{tabular}{|c|c|c|c|c|c|c|}
\hline & \multicolumn{6}{|c|}{ Imidacloprid dose $\mathrm{mg} / \mathrm{kg} / \mathrm{d}$} \\
\hline & Control & 0.03 & 0.34 & 3.42 & 10.25 & 15.5 \\
\hline PHA response $(\mathrm{mm})^{b}$ & $0.61 \pm 0.16$ & $0.61 \pm 0.17$ & $0.68 \pm 0.30$ & $0.57 \pm 0.14$ & $0.68 \pm 0.27$ & $0.62 \pm 0.21$ \\
\hline DTH response $(\mathrm{mm})^{c}$ & $0.21 \pm 0.14$ & $0.25 \pm 0.15$ & $0.23 \pm 0.17$ & $0.19 \pm 0.14$ & $0.22 \pm 0.14$ & $0.24 \pm 0.15$ \\
\hline SRBC agglutination titer ${ }^{d}$ & $4.10 \pm 1.67$ & $4.75 \pm 2.40$ & $5.27 \pm 2.26$ & $3.61 \pm 1.26$ & $4.56 \pm 1.54$ & $4.37 \pm 1.33$ \\
\hline $\mathrm{CH}_{50}$ hemolysis titer ${ }^{\mathrm{e}}$ & $11.41 \pm 6.38$ & $15.14 \pm 12.79$ & $14.21 \pm 8.36$ & $10.46 \pm 6.88$ & $13.68 \pm 8.03$ & $11.80 \pm 5.88$ \\
\hline Spleen $(\%)^{f}$ & $0.28 \pm 0.07$ & $0.30 \pm 0.06$ & $0.29 \pm 0.06$ & $0.28 \pm 0.06$ & $0.30 \pm 0.05$ & $0.27 \pm 0.06$ \\
\hline Thymus (\%) ${ }^{f}$ & $0.48 \pm 0.19$ & $0.47 \pm 0.21$ & $0.46 \pm 0.18$ & $0.47 \pm 0.18$ & $0.47 \pm 0.24$ & $0.54 \pm 0.16$ \\
\hline Bursa of Fabricius (\%) ${ }^{f}$ & $0.36 \pm 0.17$ & $0.36 \pm 0.10$ & $0.31 \pm 0.09$ & $0.34 \pm 0.15$ & $0.36 \pm 0.16$ & $0.38 \pm 0.12$ \\
\hline Liver $(\%)^{f}$ & $4.12 \pm 0.47$ & $4.19 \pm 0.37$ & $4.17 \pm 0.43$ & $4.16 \pm 0.37$ & $4.41 \pm 0.62$ & $3.98 \pm 0.33$ \\
\hline
\end{tabular}

${ }^{a}$ Mean value for each treatment group \pm standard deviation.

${ }^{\mathrm{b}}$ The phytohemagglutinin-A (PHA) response is the post PHA injection skin measurement - the pre PHA injection skin measurement

'The delayed-type hypersensitivity (DTH) response is expressed as the following ratio: (post purified protein derivative (PPD) injection measurement/ pre-PPD injection measurement) - (post saline injection measurement/pre-saline injection measurement)

${ }^{\mathrm{d}}$ The sheep red blood cell (SRBC) agglutination titers are expressed as the $\log _{2}$ of the reciprocal titer

${ }^{\mathrm{e}}$ The SRBC hemolysis results are expressed as the plasma dilution required to produce $50 \%$ lysis of the SRBCs $\left(\mathrm{CH}_{50}\right)$

fOrgan weights at necropsy are expressed as a percentage of body weight

*No statistically significant differences between treatment groups were noted

\section{Neurobehavioral abnormalities}

Chickens exposed to field-realistic doses of imidacloprid developed neurobehavioral signs ranging from mild sedation in the $3.42 \mathrm{mg} / \mathrm{kg} / \mathrm{d}$ group, to complete immobility and lack of response to external stimulation in the most severely affected birds in the $15.5 \mathrm{mg} /$ $\mathrm{kg} / \mathrm{d}$ group. Birds developed neurologic signs rapidly, occurring as quickly as 3 min after gavage. With such a swift onset of neurologic abnormalities, wild birds may quickly succumb to the effects of imidacloprid and may not be able to find cover for concealment and protection before becoming incapacitated. These moderate to severe abnormalities would compromise the ability of a wild bird to evade predation and injury, as well as to perform normal activities such as foraging for food, defending a territory, procuring a mate, and migrating (Eng, Stutchbury, and Morrissey 2017, 2019). Instances were documented in France and United States of wild birds with such severe neurologic signs due to imidacloprid toxicity that they fell from the sky and subsequently died from internal trauma (Lovy and Pietsch 2016; Millot et al. 2017). Similar hypotheses regarding impaired survival were proposed in birds exposed to other neurotoxicants such as organophosphates, but sublethal effects are challenging to document in field settings (Walker 2003).

The neurobehavioral signs observed in the present study were most likely produced by reversible binding of imidacloprid and/or imidacloprid metabolites to avian nAChRs in the nervous system and/or at neuromuscular junctions, inhibiting normal neurotransmission. Neonicotinoids eliminate insect pests by binding and overstimulating $\mathrm{nAChRs}$, resulting in paralysis, cell exhaustion and death (Jeschke et al. 2011; Simon-Delso et al. 2015). Despite the intended specificity for invertebrate $\mathrm{nAChRs,} \mathrm{imidacloprid} \mathrm{(1)} \mathrm{exhibited}$ similar excitatory effects as nicotine on nAChRs in rat brain tissue, (2) acted as an agonist at human nAChRs, and (3) initiated neurologic deficits in the offspring of rats exposed to imidacloprid (Abou-Donia et al. 2008; Kimura-Kuroda et al. 2012; Li, Ann, and Akk 2011). Mammals metabolize imidacloprid to a desnitro metabolite that binds to mammalian nicotinic receptors (D'Amour and Casida 1999). In addition, Japanese quail exposed to imidacloprid produced 5-hydroxy and olefin metabolites, 2 of the same metabolites as mammals (Bean et al. 2019). Like mammals, birds may be able to metabolize imidacloprid to a form that more readily binds to avian receptors, resulting in the observed neurobehavioral signs.

Birds that received larger doses of imidacloprid exhibited higher clinical severity scores, which suggest that larger doses resulted in more widespread nAChR stimulation, producing more severe neurobehavioral effects. Further, a direct positive correlation existed between a higher clinical severity score and a longer duration of neurobehavioral signs. The increasing severity and longer duration with rising dose follows a typical dose-response relationship, with higher doses resulting in more widespread receptor stimulation and a longer time 
for metabolism, excretion and resolution (Klassen 2008). More rapid onset of neurobehavioral signs was noted with increasing dose; however, this relationship was not significant. With neurobehavioral signs developing in under $5 \mathrm{~min}$ in the most rapid cases, wild birds might rapidly succumb to the effects of imidacloprid and may not be able to find cover before becoming incapacitated.

Neurobehavioral signs were temporary and cumulative toxicity from imidacloprid exposure was not observed. This conclusion is supported by the complete resolution of neurobehavioral signs between oral exposures, absence of increasing clinical severity scores over time and static effect levels on each exposure day. These findings suggest that chickens absorb and excrete imidacloprid relatively quickly, and that each exposure day during this $7 \mathrm{~d}$ exposure study was an independent time point with respect to neurobehavioral abnormalities rather than one, cumulative subacute exposure. This conclusion is consistent with the rapid metabolism observed in Japanese quail, where imidacloprid was no longer detectable in blood, brain, muscle, liver and kidney within $24 \mathrm{~h}$ after a single exposure to wheat seeds treated with 3 or $9 \%$ of the $\mathrm{LD}_{50}$ (Bean et al. 2019). However, more sensitive assays with lower detection thresholds than those used by Bean et al. (2019) indicate that residues might be detected in tissues at some dosing levels as long as 2 weeks post-exposure in chickens (unpublished data, in review forthcoming).

In the highest exposure group, the clinical severity score and duration of neurobehavioral signs declined significantly over time. This decline might suggest either down-regulation of nAChRs (Marks, Grady, and Collins 1993), or up-regulation of enzymes associated with chemical metabolism, such as cytochrome enzymes, resulting in more rapid chemical metabolism, decreased severity of neurobehavioral signs, and a shorter duration (Casida 2011). However, selected enzyme gene up-regulation in response to neonicotinoids was not found in male Japanese quail after one or 10 doses of oral imidacloprid (Bean et al. 2019). The underlying mechanism for higher mean clinical severity scores in males and diminishing clinical severity scores in females is unknown. Sex hormones might play a role, as male rats sustained more genotoxic effects from imidacloprid than females, which was postulated to be attributed to effects of sex hormones on imidacloprid metabolism (Arslan et al. 2016). However, the small level of the declining slopes may not translate to a biologically relevant effect on survival probability.

The decreased weight gain during the exposure period in the $15.5 \mathrm{mg} / \mathrm{kg} / \mathrm{d}$ group was likely initiated by decreased food consumption while birds were exhibiting neurobehavioral abnormalities. Growing 6 to 13 wk old birds have higher metabolic needs than adults, and therefore have a higher daily caloric requirement (Jackson and Diamond 2006). Other investigators also demonstrated reduced weight gain in growing birds associated with neonicotinoid exposure, as well as weight loss in adult birds (Eng, Stutchbury, and Morrissey 2019; Gibbons, Morrissey, and Mineau 2015; Lopez-Antia et al. 2015). The elevated weight gain in the $15.5 \mathrm{mg} / \mathrm{kg} /$ $\mathrm{d}$ group the week after the cessation of imidacloprid exposure may have been due to a compensatory increase in food consumption as a result of reduced weight gain the week prior. Decreased weight gain or weight loss secondary to imidacloprid exposure may have important survival and reproductive impacts for birds. Reduced food consumption and associated weight loss or lack of weight gain may exert severe negative effects on fitness and survival, especially during times of high energetic demand such as egglaying and migration (Eng, Stutchbury, and Morrissey 2019; Kirkwood 1991; Nilsson and Råberg 2001), or even simply impairing foraging and locomotion.

The increased crop size in the $15.5 \mathrm{mg} / \mathrm{kg} / \mathrm{d}$ group may be a reflection of enhanced food consumption preceding the daily oral exposure relative to the other birds that were neurologically normal or had a shorter duration of neurologic signs and might distribute their daily caloric intake throughout the day. However, this cannot be separated from decreased gastrointestinal motility. Delayed crop emptying has been associated with systemic disease and toxicants such as lead and organophosphates in birds (Redig and Arent 2008). Impaired gastrointestinal motility may have been a contributing factor to the increased crop size observed in the $15.5 \mathrm{mg} / \mathrm{kg} / \mathrm{d}$ birds.

\section{Effect levels for hazard and risk assessments}

The effect levels calculated in the present study provide important information regarding sublethal 
neurobehavioral effects that may impair survival of wild gallinaceous birds. Labels on widely used commercial imidacloprid products specify that soybean seeds may contain $0.16 \mathrm{mg} / \mathrm{seed}$, and wheat seeds can contain $0.033 \mathrm{mg} / \mathrm{seed}$ (Bayer CropScience LP. 2017; Mineau and Palmer 2013). For illustrative purposes, these seed application rates may be translated into an estimated number of treated seeds a bird would need to ingest to reach various exposure concentrations and exhibit subsequent effects. However, variables such as application rate, environmental degradation, and concurrent exposure to other chemicals present on treated seed might alter the anticipated numbers of seeds that need to be ingested to result in neurobehavioral signs (Gibbons, Morrissey, and Mineau 2015; Goulson 2013; Roy et al. 2019). Based on the published consumption rates of 126 untreated wheat seeds per feeding bout in an approximately $1 \mathrm{~kg}$ ring-necked pheasant (Phasianus colchicus $=4.2 \mathrm{mg} / \mathrm{kg}$ imidacloprid), and 55 untreated wheat seeds per feeding bout in an approximately $0.5 \mathrm{~kg}$ red-legged partridge $(=3.6 \mathrm{mg} / \mathrm{kg}$ imidacloprid) (Prosser and Hart 2005), these gallinaceous birds may consume enough imidacloprid treated seeds to reach the effect levels observed in the present study in a single feeding (presence of any neurobehavioral sign $\mathrm{ED}_{10}=2.19 \pm 0.51 \mathrm{mg} / \mathrm{kg} / \mathrm{d}$, $\mathrm{ED}_{50} 4.62 \pm 0.98 \mathrm{mg} / \mathrm{g} / \mathrm{d}$; adjusted score $\mathrm{ED}_{10}$ $=2.54 \pm 0.88 \mathrm{mg} / \mathrm{kg} / \mathrm{d}, \mathrm{ED}_{50} 11.24 \pm 9.33 \mathrm{mg} / \mathrm{kg} /$ $\mathrm{d} ;$ NOAEL $=3.42 \mathrm{mg} / \mathrm{kg} / \mathrm{d}$; LOAEL $=10.25 \mathrm{mg} /$ $\mathrm{kg} / \mathrm{d}$ ). This inference assumes that consumption rates between treated and untreated seeds are similar, and birds consume the published number of seeds in a single extended feeding bout.

Exposure to neonicotinoids via ingestion of treated seed has been debated based upon the removal of outer seed husks by some birds where the majority of pesticide is located (Avery, Fischer, and Primus 1997), environmental degradation of the pesticide prior to seed ingestion (Roy et al. 2019), as well as learned avoidance of treated seed after experiencing ill effects post-ingestion (Avery, Decker, and Fischer 1994; Avery et al. 1993; McGee et al. 2018). Nevertheless, toxicity due to ingestion of neonicotinoid treated seed was documented in wild birds, including neurobehavioral signs, internal trauma and death in gray partridges (Perdix perdix), pigeons (Columba sp.), cape spurfowl (Pternistis capensis) and red-winged blackbirds (Agelaius phoeniceus) (Botha et al. 2018; Gibbons, Morrissey, and Mineau 2015; Lovy and Pietsch 2016; Millot et al. 2017). Further, wild birds were reported ingesting neonicotinoid treated seed within days of seeds being available on the soil surface (Roy et al. 2019).

Risk assessors and ecological modelers might utilize these data to probe the effect of reduced activity on predation risk (as dose concentration increased) as a way of connecting these results to population-level consequences of a given exposure scenario, such as treated seed availability rates. Ecological risk assessors traditionally center their analyses on the effect of a chemical on survival, growth, or reproduction, as survival and reproduction are useful parameters for population models. Given the number of treatment groups (6) and individuals per treatment group $(\mathrm{n}=20)$, this study greatly expands data availability for deterministic and probabilistic risk assessments in which a range of probable dose concentrations might be used against a centile range of effects concentrations ("EDx" values) to determine the level of effect for a dose concentration of interest. Hazard assessment involves a comparison between appropriate effect levels (e.g., toxicity values such as NOAEL, LOAEL, or $\mathrm{ED}_{10}$ ) and dose concentrations relevant to the assessment. Birds in the present study survived, but the neurobehavioral abnormalities observed may suggest a higher probability of predation risk in the field, which may affect population trajectories through reduced survival or reproduction.

The adverse outcome pathway (AOP; Ankley et al. 2010) is a mental framework grounded in mechanistic toxicology that provides a means of considering the above information in a way that is useful for risk assessment, even when data are limited. Data gaps from the molecular to the population level may be quantitatively identified and eventually filled by investigators. If one was to consider an AOP for neurobehavioral abnormalities, the present study begins to fill the data gap linking dose concentration to behavioral effects. As no relevant AOP currently exists, correlative and mechanistically-based approaches may be used to inform the extrapolation of chicken data to other species using programs such as Web-ICE (Web-based interspecies correlation 
estimation 2019) and SeqAPASS (Sequence Alignment to Predict Across Species Susceptibility (SeqAPASS) 2019), respectively. For example, WebICE models indicate that chickens may be approximately $26 \%$ as sensitive to acute toxic effects from imidacloprid compared to sharp-tailed grouse. SeqAPASS indicates that all birds in the order Galliformes are likely susceptible to imidacloprid as indicated by $\mathrm{nAChR}$ comparisons across the class Aves (supplementary material). Such complexities aside, it is suggested that because the current study provides data centered around the key relationship between dose concentration and organismal level behavioral effects, these data may be used for risk assessments, provided uncertainties are fully described.

\section{Immune function}

Despite the reported immunotoxicity associated with neonicotinoids in birds (Kammon et al. 2012; Lopez-Antia et al. 2013, 2015), domestic chickens in the present study did not exhibit detectable immune suppression or stimulation that was clearly attributable to oral imidacloprid exposure. Possible sources of the increase in total WBC count and H/L ratio over time in all groups include handling stress, a generalized inflammatory reaction associated with the sterile abscesses from FCA, or an undetected infectious process. The rise in TS over time within all treatment groups may be a reflection of the inflammatory response to FCA, or related to increasing maturity (Ali et al. 2012; Greenacre, Luna, and Morishita 2018).

The decline in $\%$ killing of $E$. coli and C. albicans surrounding oral exposure may be an indication of immune suppression due to imidacloprid, however this cannot be confirmed as the response was not dose-dependent, and no significant differences were detected between imidacloprid treatment and control group. The fact that reduced microbicidal activity was seen only with certain doses and at certain time points may indicate that the immune response is not monotypic. The impacts of environmental stress and the inflammatory response to the FCA cannot be separated from effects of oral imidacloprid exposure. Previous E. coli vaccination is not believed to have affected the results of this study, as the microbicidal assay evaluates non-cellular components of the innate immune system present in plasma, such as naturally occurring antibodies and complement (French and Neuman-Lee 2012). The memory cells formed from previous vaccination were not present in the plasma samples employed for the in vitro microbicidal assay.

Possible explanations for the lack of observed immunotoxicity despite documentation in the literature include differences in dose, chemical, exposure method, exposure duration, and immune function assay methodology. Red-legged partridges exposed to an estimated $53 \mathrm{mg} / \mathrm{kg} / \mathrm{d}$ of imidacloprid via treated wheat seeds as the only source of food for 10 $\mathrm{d}$ demonstrated a diminished PHA response in males, but no significant effect on females and on SRBC agglutination titers (Lopez-Antia et al. 2013). A second study in red-legged partridges exposed birds to an estimated 8.8 or $44 \mathrm{mg} / \mathrm{kg} / \mathrm{d}$ of imidacloprid via treated wheat seed in 2 separate exposure periods totaling $35 \mathrm{~d}$, and a decreased PHA response was seen only in the offspring of the $8.8 \mathrm{mg} / \mathrm{kg} / \mathrm{d}$ birds; no immunotoxicity was detected in the exposed adults (Lopez-Antia et al. 2015). These investigations used higher doses, longer durations of exposure, and a different exposure method than the present study. In addition, both of the studies in red-legged partridges detected reduced cellular immunity, which may have been masked by the robust response to the FCA in the present study. Decreased humoral and cellular immunity was found in domestic chickens after exposure to sublethal doses of thiamethoxam, a different neonicotinoid (Gul et al. 2018). Exposure of 1 to $4 \mathrm{wk}$ old domestic chickens to imidacloprid at $0.05 \mathrm{mg} / \mathrm{kg} / \mathrm{d}$ for $37 \mathrm{~d}$ produced reduction in cellular and humoral immunity measured by the antibody response to Newcastle disease vaccine, serum total immunoglobulins, contact hypersensitivity to dinitrochlorobenzene (DNCB), and histopathology of the spleen and bursa of Fabricius (Kammon et al. 2012). While the imidacloprid dose and species were comparable, birds were younger and exposed for a longer duration of time than the present study, and different immune function assays were determined. While immunotoxicity was not detected in domestic chickens using the immune function assays at the doses, dosing interval, and exposure method in the present study, the potential for immunotoxicity in 
gallinaceous birds due to oral imidacloprid exposure cannot be ruled out based upon the peer-reviewed literature. However, the findings in the present study suggest that neurotoxicity appears to be a more sensitive endpoint to detect sublethal effects from oral imidacloprid exposure than immunotoxicity.

\section{Limitations}

Limitations of the present study include the route of imidacloprid exposure (the oil-based oral suspension), variable gastrointestinal contents at the time of oral exposure, selected immune function assays, and use of a model species. Granivorous birds have an extension of their esophagus called the crop which allows for food storage and gradual passage into the ventriculus for digestion (Jackson and Duke 1995). When treated seed is held in the crop and gradually passed to the ventriculus, the time to onset of neurobehavioral signs is likely different than gavage directly into the ventriculus. However, when granivorous birds ingest food with an empty gastrointestinal tract, the food bypasses the crop and immediately enters the proventriculus and ventriculus (Jackson and Duke 1995). In the latter case, the onset of neurobehavioral signs may be similar to that observed in the present study.

Oral exposure via an oil-based suspension may alter the absorption and distribution of the chemical from the gastrointestinal tract compared to a water-based suspension or force-feeding treated seeds. However, the dose-dependent neurobehavioral abnormalities noted in this study were similar to neurobehavioral abnormalities reported previously (Addy-Orduna, Brodeur, and Mateo 2019; Eng, Stutchbury, and Morrissey 2017; Millot et al. 2017). A concurrent chicken study that exposed birds to imidacloprid with the same oil-based suspension detected parent compound in blood and metabolites in feces (unpublished data, in review). This provides a strong indication that birds absorbed imidacloprid from the oil-based suspension. Imidacloprid may have been absorbed more completely or more quickly through other delivery mechanisms, but this cannot be fully elucidated with the available information.

Birds were not fasted prior to oral imidacloprid exposure, resulting in variable amounts of food in the ventriculus at the time of gavage, which may affect the absorption, distribution, metabolism and excretion of imidacloprid (Klassen 2008). If the birds had been fasted prior to exposure, the variability in time to onset and duration of neurobehavioral abnormalities may have decreased, and the severity of neurobehavioral abnormalities within an individual bird may have been more consistent from one day to the next. Nevertheless, significant differences were detected between exposure groups. Further, this may be a more accurate representation of wild birds with variable gastrointestinal contents at the time of ingestion of imidacloprid treated seed.

The FCA used in the present study generated a potent inflammatory reaction in all birds and may have masked subtle changes in cellular immune function initiated by oral imidacloprid exposure (Billiau and Matthys 2001; Dietert, Bunn, and Lee 2010). The DTH, PHA, and SRBC tests all involve contributions from T-cells (El-Lethey, HuberEicher, and Jungi 2003; Grasman 2010; Lepage, Bloom, and Taylor 1996). However, the microbicidal assay does not involve the cellular immune system (French and Neuman-Lee 2012), and is postulated to be less affected by FCA response.

Domestic chickens were used as a model for wild granivorous birds assuming that their feeding habits, behavioral and physiological attributes are sufficiently similar to justify their use. The neurologic signs observed in the present study are thought to be produced by imidacloprid and/or imidacloprid metabolites binding the avian nAChR. Therefore, some level of similar neurologic signs are likely to occur in other species with comparable receptors and metabolic pathways. However, even though Japanese quail appear to express similar $\mathrm{nAChR}$ amino acid sequences to chickens (>90\% similar, supplemental material), upon exposure to comparable concentrations of oral imidacloprid as in the present study, the quail did not develop neurobehavioral abnormalities (Bean et al. 2019). This difference may indicate that chickens are more sensitive to neurobehavioral abnormalities from oral imidacloprid than Japanese quail, quail may have a faster imidacloprid elimination rate, or may reflect a difference in methodology, as the quail were exposed with a treated seed containing multiple chemicals compared to an oil-based suspension containing neat imidacloprid (Bean et al. 2019). 


\section{Conclusions}

Domestic chickens exposed to imidacloprid at fieldrealistic doses developed temporary neurobehavioral signs in a dose-dependent manner. Toxicity was not cumulative, and the birds completely recovered between exposures, indicating that this study is more accurately viewed as a $7 \mathrm{~d}$ repeated acute exposure instead of one subacute exposure. A linear relationship existed between severity and duration of neurobehavioral signs, with higher clinical severity scores associated with a longer duration of neurobehavioral signs. Based upon the reported commercial application rate of imidacloprid on soybean seeds (Bayer CropScience LP. 2017; Mineau and Palmer 2013), a $1 \mathrm{~kg}$ bird would need to ingest only 13 treated seeds to reach the $\mathrm{ED}_{10}$ for the presence of any neurologic signs. A $1 \mathrm{~kg}$ bird would need to ingest 64 treated seeds to reach the LOAEL, which is a realistic consumption rate when wild birds are rapidly consuming food to avoid predation and compete with conspecifics. Wild birds may readily encounter this number of seeds to ingest in a single feeding session, although data in the present study indicate that birds eat less after imidacloprid exposure. Soybean seed spills numbering thousands of treated seeds per spill have been documented at an estimated rate of 11,000-21,100 spills per year during planting season in the upper Midwest (Roy et al. 2019).

The present study provides a thorough evaluation of the dose-dependent neurobehavioral signs due to oral imidacloprid exposure in chickens. Neurobehavioral abnormalities were a more sensitive indicator of the sublethal effects of imidacloprid than immunotoxicity, making this parameter more applicable to sublethal risk assessments. Three-quarters of farmland associated bird species are in decline in North America, and pesticides are a possible contributor to these declines (Stanton, Morrissey, and Clark 2018). This precise, doseresponse information regarding the sublethal neurobehavioral effects of imidacloprid in granivorous birds might be combined with information regarding the availability of this chemical in the environment and utilized in ecological risk assessments and model development to further evaluate the risk neonicotinoids pose to wild birds and guide regulations to minimize these risks.

\section{Acknowledgments}

Funding for this project was provided by the Minnesota Environment and Natural Resources Trust Fund as recommended by the Legislative-Citizen Commission on Minnesota Resources (LCCMR). Special thanks to Carlie LaLone (United States Environmental Protection Agency) for assistance with the SeqAPASS data.

\section{Disclaimer}

This research does not reflect the official positions and policies of the United States Environmental Protection Agency. Mention of products/trade names does not constitute recommendation for us by the United States Environmental Protection Agency.

\section{Declaration of interest}

The authors have no financial, commercial, legal, or professional relationships to disclose that may generate a conflict of interest regarding this research.

\section{Funding}

Funding for this project was provided by the Minnesota Environment and Natural Resources Trust Fund as recommended by the Legislative-Citizen Commission on Minnesota Resources (LCCMR);

\section{ORCID}

Dana Franzen-Klein (D) http://orcid.org/0000-0002-0365-5411

\section{Data availability statement}

Data will be available upon publication of the manuscript at https://sciencehub.epa.gov/sciencehub

\section{References}

Abou-Donia, M., L. Goldstein, S. Bullman, T. Tu, W. Khan, A. Dechkovskaia, and A. Abdel-Rahman. 2008. Imidacloprid induces neurobehavioral deficits and increases expression of glial fibrillary acidic protein in the motor cortex and hippocampus in offspring rats following in utero exposure. J. Toxicol. Environ. Health. A. 71:119-30. doi:10.1080/15287390701613140.

Addy-Orduna, L., J. Brodeur, and R. Mateo. 2019. Oral acute toxicity of imidacloprid, thiamethoxam and clothianidin in eared doves: A contribution for the risk assessment of neonicotinoids in birds. Sci. Total Environ. 650:1216-23. doi:10.1016/j.scitotenv.2018.09.112. 
Ali, M., L. Hmar, L. Inaotombi Devi, M. Prava, M. Lallianchhunga, and T. Tolenkhomba. 2012. Effect of age on the haematological and biochemical profile of Japanese quails (Coturnix coturnix japonica). Int. Multidiscip. Res. J. 2:32-35.

Ankley, G., R. Bennett, R. Erickson, D. Hoff, M. Hornung, R. Johnson, D. Mount, J. Nichols, C. Russom, P. Schmieder, et al. 2010. Adverse outcome pathways: A conceptual framework to support ecotoxicology research and risk assessment. Environ. Toxicol. Chem. 29:730-41. doi:10.1002/etc.34.

Arslan, M., Y. Sevgiler, M. Buyukleyla, M. Yardimci, M. Yilmaz, and E. Rencuzogullari. 2016. Sex-related effects of imidacloprid modulated by piperonyl butoxide and menadione in rats. Part II: Genotoxic and cytotoxic potential. Drug Chem. Toxicol. 39:81-86. doi:10.3109/ 01480545.2015.1029049.

Avery, M., D. Decker, and D. Fischer. 1994. Cage and flight pen evaluation of avian repellency and hazard associated with imidacloprid-treated rice seed. Crop Prot. 13:535-40. doi:10.1016/0261-2194(94)90107-4.

Avery, M., D. Decker, D. Fischer, and T. Stafford. 1993. Responses of captive blackbirds to a new insecticidal seed treatment. J. Wildlife Manage. 57:652-56. doi:10.2307/ 3809296.

Avery, M., D. Fischer, and T. Primus. 1997. Assessing the hazard to granivorous birds feeding on chemically treated seeds. Pestic. Sci. 49:362-66. doi:10.1002/(SICI)1096-9063(199704)49:4<>1.0.CO;2-6.

Badgujar, P., S. Jain, A. Singh, J. Punia, R. Gupta, and G. Chandratre. 2013. Immunotoxic effects of imidacloprid following 28 days of oral exposure in BALB/c mice. Environ. Toxicol. Pharmacol. 35:408-18. doi:10.1016/j.etap.2013.01.012.

Bayer CropScience LP. 2017. Gaucho 600 product label. Accessed January 9, 2019. https://s3-us-west-1.amazonaws.com/www. agrian.com/pdfs/Gaucho_600_Flowable_Label1d.pdf.

Bean, T., M. Gross, N. Karouna-Renier, P. Henry, S. Schultz, M. Hladik, K. Kuivila, and B. Rattner. 2019. Toxicokinetics of imidacloprid-coated wheat seeds in Japanese quail (Coturnix japonica) and an evaluation of hazard. Environ. Sci. Technol. 53:3888-97. doi:10.1021/acs.est.8b07062.

Billiau, A., and P. Matthys. 2001. Modes of action of Freund's adjuvants in experimental models of autoimmune diseases. J. Leukoc. Biol. 70:849-60.

Botha, C., E. Du Plessis, H. Coetser, and M. Rosemann. 2018. Analytical confirmation of imidacloprid poisoning in granivorous cape spurfowl (Pternistis Capensis). J. South Afr. Vet. Assoc. 89:e1-e5. doi:10.4102/jsava.v89i0.1637.

Brandt, A., A. Gorenflo, R. Siede, M. Meixner, and R. Büchler. 2016. The neonicotinoids thiacloprid, imidacloprid, and clothianidin affect the immunocompetence of honey bees (Apis mellifera L.). J. Insect Physiol. 86:40-47. doi:10.1016/j.jinsphys.2016.01.001.

Campbell, W., and C. Ellis. 2007. Avian \& exotic animal hematology \& cytology. 3rd ed. Oxford, UK: Blackwell Publishing.
Casida, J. 2011. Neonicotinoid metabolism: Compounds, substituents, pathways, enzymes, organisms, and relevance. J. Agric. Food Chem. 59:2923-31. doi:10.1021/jf102438c.

Costabile, M. 2010. Measuring the 50\% haemolyic complement (CH50) activity of serum. J. Vis. Exp. 37. doi:10.3791/ 1923.

D'Amour, K., and J. Casida. 1999. Desnitroimidacloprid and nicotine binding site in rat recombinant $\alpha 4 \beta 2$ neuronal nicotinic acetylcholine receptor. Pestic. Biochem. Physiol. 64:55-61. doi:10.1006/pest.1999.2409.

Dietert, R., T. Bunn, and J. Lee. 2010. The delayed type hypersensitivity assay using protein and xenogeneic cell antigens. Meth. Mol. Biol. 598:185-94.

El-Lethey, H., B. Huber-Eicher, and T. Jungi. 2003. Exploration of stress-induced immunosuppression in chickens reveals both stress-resistant and stress-susceptible antigen responses. Vet. Immunol. Immunopathol. 95:91-101. doi:10.1016/S01652427(02)00308-2.

Eng, M., B. Stutchbury, and C. Morrissey. 2017. Imidacloprid and chlorpyrifos insecticides impair migratory ability in a seed-eating songbird. Sci. Rep. 7:e57457. doi:10.1038/ s41598-017-15446-x.

Eng, M., B. Stutchbury, and C. Morrissey. 2019. A neonicotinoid insecticide reduces fueling and delays migration in songbirds. Science 365:1177-80. doi:10.1126/ science.aaw 9419.

Fairbrother, A., J. Smits, and K. Grasman. 2004. Avian immunotoxicology. J. Toxicol. Environ. Health $B$. 7:105-37. doi:10.1080/10937400490258873.

French, S., and L. Neuman-Lee. 2012. Improved ex vivo method for microbiocidal activity across vertebrate species. Biol. Open. 1:482-87. doi:10.1242/bio.2012919.

Gibbons, D., C. Morrissey, and P. Mineau. 2015. A review of the direct and indirect effects of neonicotinoids and fipronil on vertebrate wildlife. Environ. Sci. Pollut. Res. Int. 22:103-18. doi:10.1007/s11356-014-3180-5.

Goulson, D. 2013. An overview of the environmental risks posed by neonicotinoid insecticides. J. Appl. Ecol. 50:977-87. doi:10.1111/1365-2664.12111.

Grasman, K. 2002. Assessing immunological function in toxicological studies of avian wildlife. Integr. Comp. Biol. 42:34-42. doi:10.1093/icb/42.1.34.

Grasman, K. 2010. In vivo functional tests for assessing immunotoxicity in birds. In Immunotoxicity testing: Methods and protocols, ed. R. Dietert, 387-98. New York, NY: Humana Press.

Greenacre, C., G. Luna, and T. Morishita. 2018. Backyard poultry and waterfowl. In Exotic Animal Formulary, J. W. Carpenter ed., 5th ed., 376-431.

Gross, W., and H. Siegel. 1983. Evaluation of the heterophil/ lymphocyte ratio as a measure of stress in chickens. Avian Dis. 27:972-79. doi:10.2307/1590198.

Gul, S., A. Khan, M. Ahmad, H. Ahmad, M. Saleemi, M. Naseem, and M. Bilal. 2018. Immuno-toxicological effects of different sub-lethal doses of thiamethoxam (TMX) in broiler birds. Toxin Rev 38:200-05. doi:10.1080/15569543.2018.1435554. 
Jackson, S., and J. Diamond. 2006. Metabolic and digestive responses to artificial selection in chickens. Evolution 50:1638-50. doi:10.1111/j.1558-5646.1996.tb03936.x.

Jackson, S., and G. Duke. 1995. Intestine fullness influences feeding behaviour and crop filling in the domestic turkey. Physiol. Behav. 58:1027-34. doi:10.1016/0031-9384(95)00151-8.

Jeschke, P., R. Nauen, M. Schindler, and A. Elbert. 2011. Overview of the status and global strategy for neonicotinoids. J. Agric. Food Chem. 59:2897-908. doi:10.1021/jf101303g.

Kammon, A., R. Brar, H. Banga, and S. Sodhi. 2010. Pathobiochemical studies on hepatotoxicity and nephrotoxicity on exposure to chlorpyrifos and imidacloprid in layer chickens. Vet Arhiv 80:663-72.

Kammon, A., R. Brar, H. Banga, and S. Sodhi. 2012. Ameliorating effects of vitamin $\mathrm{E}$ and selenium on immunological alterations induced by imidacloprid chronic toxicity in chickens. J. Environ. Anal. Toxicol. S4:007. doi:10.4172/2161-0525.S4-007.

Kawashima, K., and T. Fujii. 2000. Extraneuronal cholinergic system in lymphocytes. Pharmacol. Ther. 86:29-48. doi:10.1016/S0163-7258(99)00071-6.

Kimura-Kuroda, J., Y. Komuta, Y. Kuroda, M. Hayashi, and H. Kawano. 2012. Nicotine-like effects of the neonicotinoid insecticides acetamiprid and imidacloprid on cerebellar neurons from neonatal rats. PLoS ONE 7:e32432. doi:10.1371/journal.pone.0032432.

Kirkwood, J. 1991. Energy requirements for maintenance and growth of wild mammals, birds and reptiles in captivity. J. Nutr. 121:S29-S34. doi:10.1093/jn/121.suppl_11.S29.

Klassen, C. 2008. Casarett and Doull's toxicology: The basic science of poisons. 7th ed. New York, NY: McGraw-Hill.

Lepage, K., S. Bloom, and R. Taylor. 1996. Antibody response to sheep red blood cells in a major histocompatibility (B) complex aneuploid line of chickens. Poult. Sci. 75:346-50. doi:10.3382/ps.0750346.

Li, P., J. Ann, and G. Akk. 2011. Activation and modulation of human $\alpha 4 \beta 2$ nicotinic acetylcholine receptors by the neonicotinoids clothianidin and imidacloprid. J. Neurosci. Res. 89:1295-301. doi:10.1002/jnr.v89.8.

Lopez-Antia, A., M. Ortiz-Santaliestra, F. Mougeot, and R. Mateo. 2013. Experimental exposure of red-legged partridges (Alectoris rufa) to seeds coated with imidacloprid, thiram and difenoconazole. Ecotoxicology 22:125-38. doi:10.1007/s10646-012-1009-x.

Lopez-Antia, A., M. Ortiz-Santaliestra, F. Mougeot, and R. Mateo. 2015. Imidacloprid-treated seed ingestion has lethal effect on adult partridges and reduces both breeding investment and offspring immunity. Environ. Res. 136:97-107. doi:10.1016/j.envres.2014.10.023.

Lovy, J., and C. Pietsch 2016. Red-winged blackbird (Agelaius phoeniceus) mortality from Bridgeton township. Case \# 16032, New Jersey Divison of Fish and Wildlife, Trenton, NJ, USA.

Luster, M., C. Portier, D. Pait, G. Rosenthal, D. Germolec, E. Corsini, B. Blaylock, P. Pollock, Y. Kouchi, W. Craig, et al. 1993. Risk assessment in immunotoxicology: II. Relationships between immune and host resistance tests. Fundam. Appl. Toxicol. 21:71-82. doi:10.1006/faat.1993.1074.

Luster, M., C. Portier, D. Pait, K. White, C. Gennings, A. Munson, and G. Rosenthal. 1992. Risk assessment in immunotoxicology: I. Sensitivity and predictability of immune tests. Fundam. Appl. Toxicol. 18:200-10. doi:10.1016/0272-0590(92)90047-L.

Marks, M., S. Grady, and A. Collins. 1993. Downregulation of nicotinic receptor function after chronic nicotine infusion. J.Pharmacol. Exp. Ther. 266:1268-76.

Martin, L., P. Han, J. Lewittes, J. Kuhlman, K. Klasing, and M. Wikelski. 2006. Phytohemagglutinin-induced skin swelling in birds: Histological support for a classic immunoecological technique. Funct Ecol 20:290-99. doi:10.1111/ j.1365-2435.2006.01094.x.

Matson, K., R. Ricklefs, and K. Klasing. 2005. A hemolysis-hemagglutination assay for characterizing constitutive innate humoral immunity in wild and domestic birds. Dev. Comp. Immunol. 29:275-86. doi:10.1016/j. dci.2004.07.006.

McGee, S., M. Whitfield-Aslund, D. Duca, N. Kopysh, T. Dan, L. Knopper, and L. Brewer. 2018. Field evaluation of the potential for avian exposure to clothianidin following the planting of clothianidin-treated corn seed. PeerJ. 6: e5880. doi:10.7717/peerj.5880.

Millot, F., A. Decors, O. Mastain, T. Quintaine, P. Berny, D. Vey, R. Lasseur, and E. Bro. 2017. Field evidence of bird poisonings by imidacloprid-treated seeds: A review of incidents reported by the French SAGIR network from 1995 to 2014. Environ. Sci. Pollut. Res. Int. 24:5469-85. doi:10.1007/s11356-016-8272-y.

Mineau, P., and C. Palmer 2013. The impact of the nation's most widely used insecticides on birds. American Bird Conservancy. Accessed December 10, 2018. http://abcbirds. org/wp-content/uploads/2015/05/Neonic_FINAL.pdf.

Nilsson, J., and L. Råberg. 2001. The resting metabolic cost of egg laying and nestling feeding in great tits. Oecologia 128:187-92. doi:10.1007/s004420100653.

Pisa, L., D. Goulson, E. Yang, D. Gibbons, F. SánchezBayo, E. Mitchell, A. Aebi, J. van der Sluijs, C. MacQuarrie, C. Giorio, et al. 2017. An update of the Worldwide Integrated Assessment (WIA) on systemic insecticides. Part 2: Impacts on organisms and ecosystems. Environ. Sci. Pollut. Res. Int. doi:10.1007/ s11356-017-0341-3.

Platt, S., S. Radaelli, and J. McDonnell. 2001. The prognostic value of the modified Glasgow coma scale in head trauma in dogs. J. Vet. Intern. Med. 15:581-84. doi:10.1111/j.19391676.2001.tb01594.x.

Prosser, P., and A. Hart. 2005. Assessing potential exposure of birds to pesticide-treated seeds. Ecotoxicology 14:679-91. doi:10.1007/s10646-005-0018-4.

$\mathrm{R}$ Core Team. 2018. R: A language and environment for statistical computing. Vienna, Austria: R-project.

Redig, P., and L. Arent. 2008. Raptor toxicology. Vet. Clin. North Am. Exot. Anim. Pract. 11:261-82. doi:10.1016/j. cvex.2007.12.004. 
Ritz, C., F. Baty, J. Streibig, and D. Gerhard. 2015. Dose-response analysis using R.”. PLoS ONE 10:13. doi:10.1371/journal. pone.0146021.

Roy, C., P. Coy, D. Chen, J. Ponder, and M. Jankowski. 2019. Multi-scale availability of neonicotinoid-treated seed for wildlife in an agricultural landscape during spring planting. Sci. Total Environ. 682:271-81. doi:10.1016/j.scitotenv.2019.05.010.

Sequence Alignment to Predict Across Species Susceptibility (SeqAPASS). 2019. v 4.0. Accessed December 11, 2019. https://seqapass.epa.gov/seqapass/.

Shores, A. 1983. Craniocerebral trauma. In Current Veterinary Therapy $X$, ed. R. W. Kirk, 847-54. Philadelphia, PA: WB Saunders.

Simon-Delso, N., V. Amaral-Rogers, L. Belzunces, J. Bonmatin, M. Chagnon, C. Downs, L. Furlan, D. Gibbons, C. Giorio, V. Girolami, et al. 2015. Systemic insecticides (neonicotinoids and fipronil): Trends, uses, mode of action and metabolites. Environ. Sci. Pollut. Res. Int. 22:5-34. doi:10.1007/s11356-0143470-y.

Smits, J., G. Bortolotti, and J. Tella. 1999. Simplifying the phytohaemagglutinin skin-testing technique in studies of avian immunocompetence. Funct. Ecol. 13:567-72. doi:10.1046/j.1365-2435.1999.00338.x.

Stanton, R., C. Morrissey, and R. Clark. 2018. Analysis of trends and agricultural drivers of farmland bird declines in
North America: A review. Agric. Ecosyst. Environ. 254:244-54. doi:10.1016/j.agee.2017.11.028.

Stephenson, G. L., and K. R. Solomo. 2017. Quantitative weight of evidence assessment higher-tier studies on the toxicity and risks of neonicotinoids in honeybees. 2. Imidacloprid. J. Toxicol. Environ. Health B. 20:330-45. doi:10.1080/10937404.2017.1388564.

van der Sluijs, J., V. Amaral-Rogers, L. Belzunces, B. van Lexmond, M. Bonmatin, J. Chagnon, M. Downs, C. Furlan, L. Gibbons, D. Giorio, et al. 2015. Conclusions of the Worldwide Integrated Assessment on the risks of neonicotinoids and fipronil to biodiversity and ecosystem functioning. Environ. Sci. Pollut. Res. Int. 22:148-54. doi:10.1007/s11356-014-3229-5.

Walker, C. 2003. Neurotoxic pesticides and behavioural effects upon birds. Ecotoxicology 12:307-16. doi:10.1023/ A:1022523331343.

Web-based interspecies correlation estimation. 2019. v 3.3. Accessed December 11, 2019. https://www3.epa.gov/ webice/.

Yamanaka, M., T. Okabe, M. Nakai, and N. Goto. 1993. Local pathological reactions and immune response of chickens to ISA-70 and other adjuvants containing Newcastle disease virus antigen. Avian Dis. 37:459-66. doi: $10.2307 / 1591673$. 